\title{
Effect of Aging Temperature on Phase Decomposition and Mechanical Properties in Cast Duplex Stainless Steels
}

\author{
Sarah Mburu, ${ }^{1, *}$, R. Prakash Kolli ${ }^{1}$, Daniel E. Perea ${ }^{2}$, Samuel C. Schwarm ${ }^{1}$, Arielle Eaton ${ }^{2}$, Jia \\ Liu $^{2}$, Shiv Patel ${ }^{1}$, Jonah Bartrand ${ }^{2}$, and Sreeramamurthy Ankem ${ }^{1}$ \\ ${ }^{1}$ Department of Materials Science \& Engineering, University of Maryland, College Park, \\ Maryland 20742 \\ ${ }^{2}$ Environmental Molecular Sciences Laboratory, Pacific Northwest National Laboratory, \\ Richland, WA 99352
}

*Corresponding Author: Sarah Mburu

Address: Department of Materials Science and Engineering

2144 Chemical and Nuclear Engineering Building, \#090

University of Maryland

College Park, MD 20742-2115, USA

E-mail: $\underline{\text { smburu@umd.edu }}$

Phone Number: 301-405-7241

Fax Number: 301-405-6327 


\begin{abstract}
The microstructure and mechanical properties in unaged and thermally aged (at $280{ }^{\circ} \mathrm{C}$, $320{ }^{\circ} \mathrm{C}, 360{ }^{\circ} \mathrm{C}$, and $400{ }^{\circ} \mathrm{C}$ to $\left.4300 \mathrm{~h}\right) \mathrm{CF}-3$ and $\mathrm{CF}-8$ cast duplex stainless steels (CDSS) are investigated. The unaged $\mathrm{CF}-8$ steel has $\mathrm{Cr}$-rich $\mathrm{M}_{23} \mathrm{C}_{6}$ carbides located at the $\delta$-ferrite $/ \gamma-$ austenite heterophase interfaces that were not observed in the $\mathrm{CF}-3$ steel and this corresponds to a difference in mechanical properties. Both unaged steels exhibit incipient spinodal decomposition into Fe-rich $\alpha$-domains and Cr-rich $\alpha$-domains. During aging, spinodal decomposition progresses and the mean wavelength (MW) and mean amplitude (MA) of the compositional fluctuations increase as a function of aging temperature. Additionally, G-phase precipitates form between the spinodal decomposition domains in $\mathrm{CF}-3$ at $360{ }^{\circ} \mathrm{C}$ and $400{ }^{\circ} \mathrm{C}$ and in $\mathrm{CF}-8$ at $400{ }^{\circ} \mathrm{C}$. The microstructural evolution is correlated to changes in mechanical properties. (146 words)
\end{abstract}

Key Words: spinodal decomposition, duplex stainless steel, atom probe tomography, $\mathrm{M}_{23} \mathrm{C}_{6}$ carbide, G-phase 


\section{Introduction}

Cast duplex stainless steels (CDSS) are used in cooling water pipes, valve bodies, pump casings, and elbows of light water nuclear reactors due to their high strength, ductility, weldability, castability, and excellent resistance to corrosion [1]. The properties of CDSS are due to their dual-phase (duplex) microstructure of body-centered cubic (b.c.c.) $\delta$-ferrite and facecentered cubic (f.c.c.) $\gamma$-austenite phases [2] and [3]. The ferrite phase is present in volume percentages (fractions) that are typically between $9 \%$ and $15 \%$ in grades used in light water nuclear reactors, such as $\mathrm{CF}-3$ and $\mathrm{CF}-8$ stainless steels [1]. Despite desirable initial properties, these steels experience degradation of mechanical properties associated with thermal aging embrittlement during extended service at operational temperatures between $280{ }^{\circ} \mathrm{C}$ and $320{ }^{\circ} \mathrm{C}$. Previous studies have reported that long-term thermal aging at operating temperature causes hardening, loss of impact toughness, and an increase in ultimate tensile strength (UTS) in these steels [1], [2], [4]-[15].

The need to extend the service life of light water nuclear reactors to 80 years from an initial design life of 40 years requires an assessment of the extent of thermal aging embrittlement of CDSS. Continuous temporal evolution of the microstructure accompanied by mechanical property degradation may prevent these steels from reaching an 80-year service life. However, performing thermal aging experiments over an 80 year cycle is impractical. An alternative approach is to perform accelerated aging experiments at higher temperatures that are kinetically similar to the operational temperatures $\left(280{ }^{\circ} \mathrm{C}-320^{\circ} \mathrm{C}\right)$. Many studies have been performed at temperatures greater than $400{ }^{\circ} \mathrm{C}$ to accelerate the microstructural aging process and are summarized in Ref. [1]. However, the physical mechanisms leading to embrittlement can vary depending on aging temperature, which can complicate the ability to make relevant comparisons 
from accelerated aging experiments. For example, while it is generally accepted that phase decomposition does not occur in the f.c.c. $\gamma$-austenite phase [12], the embrittlement process is known to involve spinodal decomposition of the b.c.c. $\delta$-ferrite phase [16] at temperatures $<400{ }^{\circ} \mathrm{C}$, where the phase decomposes into Fe-rich $\alpha$-phase domains and Cr-rich $\alpha$-phase domains. Whereas at temperatures $>400{ }^{\circ} \mathrm{C}$, embrittlement is caused by the formation of the brittle $\sigma$-phase [1], [6], [10], [16]. However, the validity of using $400{ }^{\circ} \mathrm{C}$ as an accelerated aging temperature in CDSS has been questioned due to potentially different phase decomposition kinetics and embrittlement mechanisms when compared to operational aging temperatures [1], [5], [7], [11], [17], and [18]. Besides differences caused by aging temperature, the spinodal decomposition kinetics and amount of mechanical property degradation between steels can differ depending on their composition.

In addition to spinodal decomposition, other phases such as the $\mathrm{G}-$ phase and $\mathrm{M}_{23} \mathrm{C}_{6}$ carbide can form, which further complicates analysis. The G-phase, an intermetallic nickel silicide, is known to precipitate in the ferrite phase during thermal aging. A few early studies observed G-phase precipitates in CF-8 steel but examined the steel only after aging for many years [5], [15], [19]. Some recent studies evaluated G-phase precipitate evolution in CF-3M steel, which has high molybdenum (Mo) concentration, at temperatures greater than operational temperatures [12], [20], [21], and [22]. Since G-phase precipitation at operational temperatures between $280{ }^{\circ} \mathrm{C}$ and $320{ }^{\circ} \mathrm{C}$ is not well studied in some CDSS and there exists only limited evaluation of structure-property relationship, further investigation is required. The $\mathrm{M}_{23} \mathrm{C}_{6}$ carbide phase has been observed in some CDSS with high carbon (C) concentrations. Although the $\mathrm{M}_{23} \mathrm{C}_{6}$ carbide was observed after aging for long time periods at temperatures $\geq 400{ }^{\circ} \mathrm{C}$ [5], [7], and [11], Chung and Leax [11] suggested that the carbide phase may be present in the unaged 
state of these steels. However there have been no conclusive studies to confirm this and further investigation is required. Additionally, a recent CALculation of PHAse Diagrams (CALPHAD) study indicated that the $\mathrm{M}_{23} \mathrm{C}_{6}$ carbide phase is a thermodynamically stable phase at operational temperatures [16]. Currently, the evolution and influence that these intermetallic and carbide phases have on the degradation of mechanical properties is poorly understood, and is thus the focus of the study here. Despite the aforementioned studies, less attention has been paid to the unaged steels and operational temperatures. Furthermore, microstructural evolution and mechanical property degradation differences between $\mathrm{CF}-3$ and $\mathrm{CF}-8$ at operational and accelerated temperatures are not well addressed.

In the investigation described here, we characterize the mechanical properties and microstructure of CF-3 and CF-8 CDSS in both an unaged state and thermally aged for $4300 \mathrm{~h}$ at operational temperatures of $280{ }^{\circ} \mathrm{C}$ and $320{ }^{\circ} \mathrm{C}$, and accelerated aging temperatures of $360{ }^{\circ} \mathrm{C}$ and $400{ }^{\circ} \mathrm{C}$. We characterize and discuss the $\mathrm{Cr}$-rich $\mathrm{M}_{23} \mathrm{C}_{6}$ carbide phase that is present in the unaged $\mathrm{CF}-8$ steel by atom probe tomography (APT) and transmission electron microscopy (TEM). In contrast, we did not observe the $\mathrm{Cr}$-rich $\mathrm{M}_{23} \mathrm{C}_{6}$ carbide phase in the unaged $\mathrm{CF}-3$ steel. The sub-nanometer spatial resolution and high elemental sensitivity of the APT technique permits three-dimensional (3D) visualization of internal features [23] and [24], while TEM permits a wider field-of-view (FOV) than APT and acquisition of crystal structure information. We also assess the influence of the local Cr concentration on phase decomposition within the ferrite phase. We evaluate differences in the early stages of spinodal decomposition between the steels using APT. We measure amplitude and wavelength of concentration fluctuations in the ferrite phase that are consistent with the Cahn-Hilliard theory of spinodal decomposition [25], [26], and compare it to values of wavelength determined by the auto-correlation function (ACF) 
method [27] and amplitude determined by the Langer-Bar-on-Miller (LBM) method [28]. In general, we characterize the differences in phase decomposition - including spinodal domains and the $\mathrm{G}-$ phase in $\mathrm{CF}-3$ and $\mathrm{CF}-8$ when aging at different temperatures, and relate these results to mechanical property degradation of the two steels.

\section{Experimental Procedures}

\subsection{Materials}

The steels investigated in this study were obtained from Monett Company, Inc. as $17.8 \mathrm{~cm} \times 3.3 \mathrm{~cm} \times 2.9 \mathrm{~cm}$ rectangular keel blocks that were cast to the $\mathrm{CF}-3$ and $\mathrm{CF}-8$ standard specification outlined by ASTM A351-12b. All blocks of each steel type were cast from the same melt followed by a solution treatment at $1065^{\circ} \mathrm{C}(1338 \mathrm{~K})$ for $2 \mathrm{~h}$ and quenched in water at room temperature in accordance with the ASTM standard. The nominal chemical composition of the two steels as measured by optical emission spectroscopy (OES) is provided in Table 1 . The keel blocks were mechanically reduced into $1.6 \mathrm{~cm} \times 1.6 \mathrm{~cm} \times 5.8 \mathrm{~cm}$ Charpy V-notch $(\mathrm{CVN})$ and $1.6 \mathrm{~cm} \times 1.6 \mathrm{~cm} \times 8.9 \mathrm{~cm}$ tensile specimen blanks. The blanks were thermally aged in air to $4300 \mathrm{~h}$ in four Thermolyne ${ }^{\mathrm{TM}}$ Benchtop Muffle Furnaces at temperatures of $280{ }^{\circ} \mathrm{C}, 320^{\circ} \mathrm{C}, 360^{\circ} \mathrm{C}$, and $400{ }^{\circ} \mathrm{C}$. Subsequently, the blanks were computer numerical control (CNC) machined into test specimens in accordance with the ASTM standard procedures, as described below.

\subsection{Mechanical Properties}

\subsubsection{Charpy V-notch (CVN) Impact Toughness}


The CVN specimens were fabricated in accordance with the ASTM E23-12c standard from the specimen blanks. The $55 \mathrm{~mm} \times 10 \mathrm{~mm} \times 10 \mathrm{~mm} \mathrm{CVN} \mathrm{specimens} \mathrm{were} \mathrm{tested}$ employing a Tinius Olsen IT406 test frame at room temperature following the ASTM standard test procedures. The absorbed impact energy was measured and fracture morphology was observed for each specimen. The average of two or three measurements was reported for each aging condition, and the reported errors were based on the standard error of the mean.

\subsubsection{Vickers Microhardness}

Specimen blanks were mechanically reduced and cold mounted in epoxy for metallographic specimen preparation. The mounted specimens were ground and polished to 0.3 $\mu \mathrm{m}$ surface finish employing standard procedures. The polished specimens were tested using an Instron Tukon 2100 tester with a Vickers microhardness indenter, a load of $500 \mathrm{~g}$, and dwell time of $15 \mathrm{~s}$ in accordance with the ASTM E384-11 standard procedures. The average of ten measurements was reported and the $\pm 2 \sigma$ errors were based on the standard error of the mean.

\subsubsection{Tensile Test}

Cylindrical test specimens with a gauge diameter of $6.35 \mathrm{~mm}$ and a gauge length of 25.4 mm were fabricated in accordance with the ASTM E8-13a standard. Tensile tests were performed employing an Instron 8502 test frame equipped with an 8800 controller in accordance with the ASTM standard procedure. A preload of $~ 100 \mathrm{~N}$ was applied before the start of each test and a calibrated extensometer with $50 \%$ elongation capability was used for continuous measurement of strain using strain-rate control rate of $0.00025 \mathrm{~s}^{-1}$. The extensometer was removed at its elongation limit and the tensile specimens were tested to failure using crosshead 
speed control rate of $0.006125 \mathrm{~mm} \mathrm{~s}^{-1}$ while measuring load and displacement. The ultimate tensile strength (UTS) was determined following the procedures outlined in the ASTM standard procedure.

\subsection{Optical and Electron Microscopy}

Optical microscopy was performed employing a Buehler ${ }^{\circledR}$ ViewMet Inverted Metallograph. The metallographic specimens were etched with Kalling's reagent No. 1 following standard procedures at room temperature to reveal the dual-phase microstructure.

Scanning electron microscope/focused ion beam (SEM/FIB) observations were performed employing a FEI Helios Nanolab 600 dual-beam instrument at $5 \mathrm{keV}$.

Transmission electron microscope (TEM) specimens for both unaged $\mathrm{CF}-3$ and $\mathrm{CF}-8$ steels were prepared by mechanical thinning to a thickness of approximately $200 \mu \mathrm{m}$ before punch-out of $3 \mathrm{~mm}$ diameter foils. The foils were single-jet electropolished in $10 \mathrm{vol} . \%$ perchloric acid $\left(\mathrm{HClO}_{4}\right)$ solution in acetic acid $\left(\mathrm{CH}_{3} \mathrm{COOH}\right)$ at $0{ }^{\circ} \mathrm{C}$ and $20 \mathrm{~V}$ for 10 minutes. The foils were then subsequently ion-beam milled at a $10^{\circ}$ milling angle, $5 \mathrm{kV}$, and $3 \mathrm{~mA}$ until perforation in a Fischione Model 1010 milling system. The $\delta$-ferrite $/ \gamma$-austenite heterophase interfaces were observed by a JEOL $2100 \mathrm{LaB}_{6}$ TEM instrument operated at $200 \mathrm{kV}$ and a JEOL 2100 field emission gun (FEG) TEM instrument operated at $200 \mathrm{kV}$ equipped with an Oxford INCA 250 X-ray energy dispersive spectrometer (EDS). The selected area electron diffraction (SAED) technique was used to identify the $\delta$-ferrite, $\gamma$-austenite, and $\mathrm{M}_{23} \mathrm{C}_{6}$ carbide phases in the foils. The TEM images and SAED patterns were analyzed using the Gatan Digital Micrograph Microscopy Suite software. 


\subsection{Atom Probe Tomography (APT)}

\subsubsection{Atom Probe Tomography Specimen Preparation}

Specimens with a needle-shaped geometry necessary for APT analysis were fabricated using a FEI Helios Nanolab 600 dual-beam SEM/FIB instrument following standard lift-out and sharpening procedures [29], [30]. The in situ site-specific specimen preparation technique was performed on the metallographic mounts to take APT specimen blanks from $\delta$-ferrite $/ \gamma$-austenite heterophase interfaces, Figs. 1(a) - (b). To create the needle-shaped morphology necessary for APT analysis, annular milling was performed employing a $30 \mathrm{keV}$ gallium ion $\left(\mathrm{Ga}^{+}\right)$ion beam and sequentially decreasing probe currents following standard procedures after transfer of the region of interest $(\mathrm{ROI})$ to the silicon $(\mathrm{Si})$ microtip post with an Omniprobe micromanipulator, Figs. 1(c) - (e) [31]. As a final step, a low $\mathrm{keV}$ ion beam of $2 \mathrm{keV}$ was allowed to raster over the specimen tip to remove material that had been damaged by the $30 \mathrm{keV} \mathrm{Ga}^{+}$ion beam annular milling operation [30]. The final apex of the specimen tips, imaged by SEM using $5 \mathrm{keV}$, had radii of $\leq \sim 50 \mathrm{~nm}$ suitable for APT analysis.

\subsubsection{Atom Probe Tomography Data Acquisition, Reconstruction, and Data Analysis}

A CAMECA Local-Electrode Atom Probe $\left(\right.$ LEAP $\left.^{\circledR}\right)$ 4000X instrument in the HR configuration, equipped with a reflectron for high mass resolution, was used for APT analysis. The specimen tip base temperature during data acquisition was set at $40 \mathrm{~K}$. A voltage pulsed mode was applied to the specimen tips with a pulse-to-standing DC voltage ratio of between $15 \%$ and $20 \%$ at a pulse frequency of $200 \mathrm{kHz}$ to promote field evaporation. The evaporation rate was maintained at a constant $1.5 \%$ rate or 0.015 ions per pulse. The background pressure was $\sim 1.6 \times 10^{-11}$ Torr $\left(2.1 \times 10^{-9} \mathrm{~Pa}\right)$. In order to precisely determine the time-of-flight (TOF) 
of the ions and thus their mass-to-charge state $(\mathrm{m} / \mathrm{n})$ ratios, we confirmed that the aforementioned pulse fraction range resulted in a lower probability of tip fracture, low background noise signal, and low incidences of multiple hits. Data sets of greater than four million ions were collected for each specimen tip, which corresponds to analysis depths of $60 \mathrm{~nm}$ to $120 \mathrm{~nm}$ depending on the tip radius. Data reconstruction and analysis were performed using the CAMECA Integrated Visualization and Analysis Software (IVAS), version 3.6.8. The APT specimen tips were reconstructed with a radius evolution defined using the tip profile morphology from SEM micrographs taken before APT analysis. Overlapping iron $(\mathrm{Fe})$ and chromium $(\mathrm{Cr})$ mass peaks at an $\mathrm{m} / \mathrm{n}$ ratio of 54 were deconvoluted based on isotopic abundances.

The $\delta$-ferrite/ $\gamma$-austenite heterophase interfaces were delineated by a 4.5 at.\% nickel (Ni) isoconcentration surface and associated proximity histogram concentration profiles [32] were used for compositional analysis [33]. The $\pm 2 \sigma$ error bars were derived from counting statistics. The $\delta$-ferrite phase and $\gamma$-austenite phase compositions were derived from the ion counts using only the plateau points [33] at a far-field distance of between $5 \mathrm{~nm}$ and $10 \mathrm{~nm}$ from the heterophase interfaces with $\pm 2 \sigma \leq 0.25$ at.\%. An analysis was performed to isolate the $\mathrm{M}_{23} \mathrm{C}_{6}$ carbide phase in the $\mathrm{CF}-8$ steel and determine its composition using a $1 \mathrm{~nm} \times 1 \mathrm{~nm} \times 30 \mathrm{~nm}$ rectangular ROI and associated one-dimensional (1D) concentration profile. A small crosssection was chosen for the ROI in order to determine the core concentration of the carbide phase.

For spinodal decomposition analysis, a rectangular ROI of dimensions $3.2 \mathrm{~nm} \times 3.2 \mathrm{~nm} \times$ $30 \mathrm{~nm}$ was created in the ferrite phase of each unaged steel. The ROI was positioned at a distance of at least $1 \mathrm{~nm}$ away from the heterophase interfaces. The $\mathrm{Fe}$ (blue) and $\mathrm{Cr}$ (magenta) concentration profiles were determined using a fixed bin width of $0.2 \mathrm{~nm}$. The initial 
concentration profile data was smoothed using a triangular 3-point moving average defined by $T_{i}=\frac{1}{4}\left(t_{i-2}+2 t_{i-1}+t_{i}\right)$ for bins $i \geq 3$, where $t_{i}$ is the initial data set and $T_{i}$ is the smoothed data set. The smoothed profiles were plotted with the mean of the $\mathrm{Fe}$ and $\mathrm{Cr}$ concentration profiles, which were derived from the ion counts in each bin, Figs. 2(a) - (b). The $\pm 2 \sigma$ error bars of the mean $\mathrm{Fe}$ and $\mathrm{Cr}$ concentrations were derived from counting statistics. The alternating $\mathrm{Fe}$ and $\mathrm{Cr}$ concentration fluctuations were defined in the same method. A Cr concentration fluctuation was defined as when the concentration was greater than its mean value $+2 \sigma$ and concomitantly the Fe concentration fluctuation was less than its mean value. Similarly, the Fe concentration fluctuation was defined as when its concentration was greater than its mean value $+2 \sigma$ and concomitantly the $\mathrm{Cr}$ concentration fluctuation was less than its mean value. Thus, the periodic alternating fluctuations are defined along the ROI. We consider here that the amplitude of a concentration fluctuation, $A$, of $\mathrm{Fe}$ or $\mathrm{Cr}$ was defined as the highest point from the mean concentration value of that element, $A_{j}^{k}=C_{j}^{k}(\max )-\bar{C}_{j}$, where $j$ is the element and $k$ is the peak number. The wavelength, $\lambda$, of Fe or $\mathrm{Cr}$ was defined as the distance between two adjacent amplitudes of a concentration fluctuation, $\lambda_{j}^{k}=x_{j}^{k+1}-x_{j}^{k}$, where $x$ is the distance along the concentration profile, $j$ is the element, and $k$ is the peak number. The methodology discussed above is consistent with evaluation of wavelength and amplitude for periodic concentration fluctuations, and extant methods evaluate these quantities independently [34]. The above analysis was repeated using 20 non-overlapping rectangular ROIs in order to determine wavelength and amplitude size distributions. The wavelength (in $\mathrm{nm}$ ) and amplitude (in at.\%) size distribution histograms were plotted with a bin size of 0.5 for the ferrite phase of both the CF-3 and CF-8 steels. The mean wavelength (MW) and the mean amplitude (MA) were derived from the histograms. Deviation of the ROI cross-sectional dimension within a certain range did 
not significantly affect the wavelength and amplitude size distributions, thereby indicating a numerically stable evaluation procedure. Binomial distribution functions, which represent the distribution of random wavelengths and amplitudes, were superimposed on the histograms for comparative analysis. The mean wavelength results were compared with those obtained using the ACF method [27] using a bin size of $0.2 \mathrm{~nm}$ and the same rectangular ROI's. The mean amplitude results were compared with those determined by the LBM method [28] using a bin (block) size of 100 atoms and the same rectangular ROI's.

The G-phase precipitates in the APT reconstructions were delineated by 6.5 at.\% Ni isoconcentration surfaces. The precipitate volume equivalent sphere radii, $\langle R\rangle$ [33], number density, $N_{V}$, volume percentage (fraction), $V_{f}$, and core compositions are reported. The estimated steel density, $\rho$, is $8.46 \times 10^{22}$ atoms $\mathrm{cm}^{-3}$, which was used to calculate the reconstructed volumes of the APT specimen tips [33] and the estimated detection efficiency, $\eta$, is $36 \%$ for this atom probe instrument. The $\mathrm{G}$-phase core compositions were derived from the four data points on the right hand side of the proxigram concentration profiles. Deviations of the isoconcentration surface threshold value within a certain concentration range did not significantly change the number of detected precipitates or their proxigrams thereby indicating a numerically stable evaluation procedure.

\section{Results and Discussion}

\subsection{Mechanical Properties}

\subsubsection{Vickers Microhardness}

The results in Fig. 3(a) illustrate that the unaged $\mathrm{CF}-3$ has a lower mean Vickers microhardness value of $151.8 \pm 4.6 \mathrm{HV} 500 \mathrm{~g}$, whereas the unaged CF-8 in Fig. 3(d) has a greater 
mean value of $165.8 \pm 5.8 \mathrm{HV} 500 \mathrm{~g}$. As we discuss below, this difference is possibly caused by the presence of the $\mathrm{M}_{23} \mathrm{C}_{6}$ carbide phase at the heterophase interfaces in the $\mathrm{CF}-8$ steel but not the $\mathrm{CF}-3$ steel. Additionally, $\mathrm{C}$ is well known to cause interstitial solid-solution hardening and the nominal concentration of $\mathrm{C}$ in the $\mathrm{CF}-8$ steel is greater than in the $\mathrm{CF}-3$ steel. The mean Vickers microhardness increased for both steels after aging to $4300 \mathrm{~h}$ due to phase decomposition, as discussed below. The rates of microhardness increase, as indicated by the slopes of the trend lines in Figs. 3(a) and 3(d) is approximately twice as great at the accelerated temperatures than at the operational temperatures. The slopes are greater for the $\mathrm{CF}-3$ steel than the $\mathrm{CF}-8$ steel in general indicating that the microhardness increases faster for $\mathrm{CF}-3$. However, after aging, the microhardness values of the two steels are comparable at all four temperatures. The mean microhardness values are greater after aging at accelerated temperatures than operational temperatures for both steels.

\subsubsection{Tensile Properties}

The unaged CF-3 steel has a UTS value of $530 \mathrm{MPa}$, in Fig. 3(b), and the unaged CF-8 steel has a UTS of $570 \mathrm{MPa}$, Fig. 3(e). The higher strengths in the CF-8 steel may possibly be due to the presence of the $\mathrm{M}_{23} \mathrm{C}_{6}$ carbide phase at the heterophase interfaces. The higher Vickers microhardness and UTS values are consistent with the $\mathrm{M}_{23} \mathrm{C}_{6}$ carbide phase acting to strengthen the unaged $\mathrm{CF}-8$ steel when compared to the unaged $\mathrm{CF}-3$ steel. This result is similar to that of Mathew, et al. [35], who reported a UTS of $\sim 600 \mathrm{MPa}$ for a CF-8 steel. Additionally, Michaud, et al. [36] performed tensile property characterization of $\mathrm{CF}-3$ and $\mathrm{CF}-8$ steels and reported a UTS of $~ 390 \mathrm{MPa}$ for CF-3 steel, while the CF-8 steel exhibited a UTS of 525 MPa. The trend is consistent with the steels in this study, where $\mathrm{CF}-8$ steel has higher UTS than the CF-3 steel. 
The mean UTS increased for both steels after aging to $4300 \mathrm{~h}$ at the accelerated temperatures and the values were similar between the steels. A difference in behavior was observed when aging at the two operational temperatures. The mean UTS increased for both steels when aging at $320{ }^{\circ} \mathrm{C}$ but it only increased for $\mathrm{CF}-8$ and not $\mathrm{CF}-3$ when aging at $280{ }^{\circ} \mathrm{C}$. Furthermore, a difference in mean UTS values still existed between the two steels, unlike when aging at accelerated temperatures. The rates of UTS increase, as indicated by the slopes of the trend lines in Figs. 3(b) and 3(e) is more than twice as great at the accelerated temperatures than at the operational temperatures. The slopes are greater for the $\mathrm{CF}-3$ steel than the $\mathrm{CF}-8$ steel in general indicating that the UTS increases faster for the CF-3. However, the mean UTS values were greater after aging at accelerated temperatures than operational temperatures.

\subsubsection{Charpy V-notch Impact Toughness (CVN)}

As illustrated in Fig. 3(f), the lower CVN impact toughness value of the unaged CF-8 of $317 \pm 80 \mathrm{~J}$ as compared to the unaged CF-3 of $392 \pm 14 \mathrm{~J}$ in Fig. 3(c) is most likely due to the presence of $\mathrm{M}_{23} \mathrm{C}_{6}$ carbides at the heterophase interfaces. Carbides located at the heterophase interfaces may influence the failure mode by causing phase boundary separation thereby leading to low impact toughness values [13]. Previous research also demonstrated a similar trend where an as-cast CF-3 steel [8] had a higher upper shelf energy of > $300 \mathrm{~J}$ when compared to the unaged CF-8 steel [19], which had an upper shelf energy of $225 \mathrm{~J}$. The mean CVN values decreased for both steels after aging to $4300 \mathrm{~h}$ at all four temperatures and the mean values were similar between the steels at the accelerated temperatures. At operational temperatures, the $\mathrm{CF}-8$ steel exhibited a greater reduction in mean $\mathrm{CVN}$ values when compared to $\mathrm{CF}-3$. Furthermore, a difference in mean $\mathrm{CVN}$ values still existed between the two steels unlike when aging at 
accelerated temperatures. The mean $\mathrm{CVN}$ values were lower after aging at accelerated temperatures than operational temperatures and both steels exhibited the lowest CVN value when aging at $400{ }^{\circ} \mathrm{C}$. The unaged specimens exhibited ductile fracture with significant deformation and did not completely break. All aged specimens exhibited more brittle fracture with less deformation and more granular fracture surfaces. The rates of impact toughness decrease, as indicated by the slopes of the trend lines in Figs. 3(c) and 3(f) is more than twice as great at the accelerated temperatures than at the operational temperatures. The slopes are greater for the $\mathrm{CF}_{-}$ 3 steel than the $\mathrm{CF}-8$ steel indicating that the impact toughness decreases faster in $\mathrm{CF}-3$.

\subsection{Microstructural Characterization}

\subsubsection{Optical Microscopy: Microstructure}

An optical micrograph, Fig. 4, illustrates a microstructure consisting of a network of island-shaped $\delta$-ferrite phase (dark color) in the continuous $\gamma$-austenite phase (light color) for the unaged $\mathrm{CF}-3$ steel. The microstructure of the unaged $\mathrm{CF}-8$ steel has a qualitatively similar appearance to that of the CF-3 steel. The ferrite volume percentage is $11.5 \pm 1.1 \%$ for the CF-3 steel while that of the $\mathrm{CF}-8$ steel is $9.1 \pm 0.9 \%$ as measured by the manual point counting method specified in the ASTM E562-11 standard [37] and [38]. The microstructure observed in this study is consistent with that reported in the literature of a steel with a composition similar to CF-8 and with a ferrite volume percentage of less than $20 \%$ [39], [40]. The ferrite volume percentage remained approximately constant when aging to $4300 \mathrm{~h}$ at all four temperatures.

\subsubsection{Atom Probe Tomography (APT) and Transmission Electron Microscopy (TEM): $M_{23} C_{6}$}

Carbide at the Heterophase Interfaces 
The proximity histogram (proxigram) concentration profiles across the $\delta$-ferrite $/ \gamma$ austenite heterophase interfaces are qualitatively similar for the unaged $\mathrm{CF}-3$ and $\mathrm{CF}-8$ steels, Figs. 5(a) - (b) and 6(a) - (b), respectively. However a distinct carbide phase is observed in the $\mathrm{CF}-8$ reconstruction, Fig. 6(a). The peak $\mathrm{C}$ concentration at the heterophase interface is $\sim 0.8$ at. $\%$ for the $\mathrm{CF}-3$ steel and $\sim 1.5$ at.\% for the $\mathrm{CF}-8$ steel, which is influenced by the presence of a carbide phase. As discussed below, this carbide phase is identified as the $\mathrm{M}_{23} \mathrm{C}_{6}$ carbide. Since the $\mathrm{CF}-8$ steel has a greater nominal $\mathrm{C}$ concentration than the $\mathrm{CF}-3$ steel, the thermodynamic driving force for carbide formation at the heterophase interfaces is greater [16]. A more detailed analysis, Figs. 7(a) - (d), was performed to determine the $\mathrm{M}_{23} \mathrm{C}_{6}$ carbide phase composition. The carbides are interspersed along the $\delta$-ferrite $/ \gamma$-austenite heterophase interface of the APT specimen tip, Fig. 7(a), and an example carbide is visible in the APT reconstructions, Figs. 7(b) (c). The $\mathrm{Cr}$ and $\mathrm{C}$ are enriched, while $\mathrm{Fe}$ and $\mathrm{Ni}$ are depleted within the carbide phase (black box) relative to the austenite phase, Fig. $7(\mathrm{~d})$. The carbide composition is $32.5 \pm 2.1$ at. $\% \mathrm{Fe}$, $49.2 \pm 1.5$ at. $\%$ Cr, $11.9 \pm 1.2$ at.\% C, $2.0 \pm 0.4$ at.\% Mo, $2.1 \pm 0.7$ at.\% Ni, $1.1 \pm 0.2$ at.\% Mn, and $0.65 \pm 0.14$ at. $\%$ Si. Recent CALPHAD calculations indicate that the most common carbide present in $\mathrm{CF}-8$ steels is the f.c.c. $\mathrm{M}_{23} \mathrm{C}_{6}$ carbide, where $\mathrm{M}=\mathrm{Cr}$ [16]. Since the steels were cast, solution-treated, and quenched in water at room temperature, the carbide composition in the unaged state is most likely not yet at equilibrium.

The $\delta$-ferrite $/ \gamma$-austenite heterophase interfaces in both unaged steels were also observed by conventional TEM. The interfaces of the unaged CF-3 steel were consistently straight and uniform and did not exhibit a carbide phase as demonstrated by the lack of superlattice reflection spots in the SAED pattern, Fig. 8(a) inset. Carbides were also not observed in the b.c.c. $\delta$-ferrite phase or the f.c.c. $\gamma$-austenite phase grains at locations away from the heterophase interfaces. 
The lack of carbides in the microstructure is most likely due to the low nominal C concentration, Table 1. In contradistinction, the interfaces in the $\mathrm{CF}-8$ steel were noticeably more undulating than in the CF-3 steel, Fig. 8(b), and SAED patterns taken at the interfaces along the [001], Fig. 8(b) inset, and [301], Fig. 9(c), $\gamma$-austenite zone axes reveal the presence of f.c.c. superlattice diffraction spots indicative of an $\mathrm{M}_{23} \mathrm{C}_{6}$ carbide phase. These spots are not, however, present in the SAED patterns at the interior of either the $\delta$-ferrite phase or $\gamma$-austenite phase grains. Additionally, the $\mathrm{M}_{23} \mathrm{C}_{6}$ carbide and $\gamma$-austenite phase exhibit a cube-cube orientation relationship (OR) of $\{111\}_{\gamma}\left\|\{333\}_{M_{23} C_{6}},\langle 110\rangle_{\gamma}\right\|\langle 330\rangle_{M_{23} C_{6}}$. The $\mathrm{M}_{23} \mathrm{C}_{6}$ carbide has an elongated morphology, Figs. 9(a) - (b), with a length of $\sim 230 \mathrm{~nm}$ and width of $\sim 90 \mathrm{~nm}$. Other carbides of the same type were observed at multiple different heterophase interfaces in $\mathrm{CF}-8$, and exhibit a morphology similar to the one illustrated in Figs. 9(a) - (b). The lattice parameter, $a$, was measured as $1.109 \mathrm{~nm}$ in this study, which is slightly greater than the experimental value of $a=1.065 \mathrm{~nm}$ reported by Southwick and Honeycombe in a different DSS [41]. It is also similar to other values reported in the literature of approximately between $1.05 \mathrm{~nm}$ and $1.10 \mathrm{~nm}$ [42], [43]. The lattice parameter is known to exhibit small variations due to differences in chemical composition [38]-[40].

A TEM-EDS line-scan was taken from the interior of the $\delta$-ferrite phase grain across an $\mathrm{M}_{23} \mathrm{C}_{6}$ carbide and ending in the interior of the $\gamma$-austenite phase grain, Fig. 9(d). The results illustrate that the carbide is enriched in $\mathrm{Cr}$ and $\mathrm{C}$, and contains smaller quantities of $\mathrm{Mn}, \mathrm{Ni}, \mathrm{Mo}$, and $\mathrm{Si}$. The carbide is depleted in $\mathrm{Fe}$ and $\mathrm{Ni}$ when compared to the adjacent ferrite and austenite phases. Furthermore, a depletion of $\mathrm{Cr}$ in the b.c.c. $\delta$-ferrite phase is observed up to a distance of approximately $50 \mathrm{~nm}$ away from the heterophase interface, which suggests the presence of a solute depleted zone (SDZ). These observations support the APT observations that the $\mathrm{M}_{23} \mathrm{C}_{6}$ 
carbide contains metallic elements other than Cr. Additionally, earlier STEM-EDS observations in a different steel containing a smaller nominal concentration of $2.6 \mathrm{wt}$. $\% \mathrm{Cr}$ also indicated that $\mathrm{M}_{23} \mathrm{C}_{6}$ carbides contain metallic elements other than $\mathrm{Cr}$ [44]. Recent first principles calculations of a model ternary alloy also illustrate that $\mathrm{Fe}$ can substitute on the $\mathrm{Cr}$ lattice forming a $\mathrm{Cr}_{23}$ ${ }_{\mathrm{x}} \mathrm{Fe}_{\mathrm{x}} \mathrm{C}_{6}$ carbide [42].

The occurrence of the SDZ in the ferrite phase of CF-8 and not CF-3 suggests that the Cr-rich carbides locally influence the phases' composition. Additionally, the SDZ formation in the ferrite phase and not the austenite phase suggests that differences in $\mathrm{Cr}$ diffusivity in each phase also influence its formation. Since $\mathrm{Cr}$ is the predominant metallic element in the $\mathrm{M}_{23} \mathrm{C}_{6}$ carbide [45], its nonstoichiometric composition in the unaged $\mathrm{CF}-8$ suggests that $\mathrm{Cr}$ diffuses into the carbide during aging while $\mathrm{Fe}, \mathrm{Mo}, \mathrm{Ni}, \mathrm{Mn}$, and Si most likely diffuse into the surrounding matrix phases thereby permitting its composition to approach equilibrium. In addition, since the $\mathrm{M}_{23} \mathrm{C}_{6}$ carbide is located at the heterophase interface, enhanced or short circuit diffusion of $\mathrm{Cr}$ from the ferrite phase into the carbide phase along the interface may occur. The diffusion of solute elements at grain boundaries and heterophase interfaces can be several orders of magnitude greater than in the bulk volume [46], [47], and the formation of the SDZ in the ferrite phase of the unaged $\mathrm{CF}-8$ suggests that the kinetics are fastest at the heterophase interface. The influence of the $\mathrm{M}_{23} \mathrm{C}_{6}$ carbide on the local $\mathrm{Cr}$ concentration at the heterophase interface and formation of an SDZ in the ferrite phase of $\mathrm{CF}-8$ but not $\mathrm{CF}-3$ is supported by APT observations where we measure a mean $\mathrm{Cr}$ concentration of 24.9 at.\% for CF-8, Fig. 6(b), and 28.7 at.\% in the ferrite phase for CF-3, Fig. 5(b). The mean $\mathrm{Cr}$ concentration is 22.3 at.\% in the austenite phase of both steels. Hence, formation of the carbide locally depletes the Cr concentration in the ferrite phase of $\mathrm{CF}-8$. A similar SDZ was observed at a grain boundary (GB) in a 
multicomponent $\mathrm{Fe}-\mathrm{Cu}$ steel due to the presence of an $\mathrm{Fe}_{3} \mathrm{C}$ carbide at the interface and was also attributed to more rapid kinetics [48].

We now consider the differences in diffusivity of $\mathrm{Cr}$ between the two phases. Williams and Faulkner studied Cr diffusion in ferritic and austenitic steels [49] and found that Cr in b.c.c. ferrite had a diffusion constant of $D_{o}=0.15\left(\frac{+0.54}{-0.12}\right) \mathrm{cm}^{2} \mathrm{~s}^{-1}$ and activation energy of $Q=$ $210( \pm 15) \mathrm{kJ} \mathrm{mol}^{-1}$, whereas Cr in f.c.c. austenite had a diffusion constant of $D_{o}=$ $0.27\left(\frac{+1.04}{-0.22}\right) \mathrm{cm}^{2} \mathrm{~s}^{-1}$ and $Q=264( \pm 16) \mathrm{kJ} \mathrm{mol}^{-1}$. The Arrhenius diffusion equation of $\mathrm{Cr}$ is $\bar{D}_{C r}=D_{o} e^{-Q / R T}$, where $R$ is the gas constant $8.31 \mathrm{~J}(\mathrm{~mol} \mathrm{~K})^{-1}$ and $T$ is the absolute temperature. The diffusion distance during solution treatment can be determined to a first order approximation using the solution treatment temperature of $1338 \mathrm{~K}\left(1065^{\circ} \mathrm{C}\right)$. The $3 \mathrm{D}$ rootmean-square (RMS) diffusion distance of $\mathrm{Cr},\left\langle x_{C r}\right\rangle=\sqrt{6 \times \bar{D}_{C r} \times t}$, is $64.1 \mu \mathrm{m}$ in ferrite, and $7.6 \mu \mathrm{m}$ in austenite where $t$ is the solution treatment time of $7200 \mathrm{~s}$. Thus, Cr has a diffusion distance in the ferrite phase an order of magnitude greater than in the austenite phase for the same time interval indicating that the $\mathrm{Cr}$ diffusion kinetics are more rapid in ferrite thereby promoting the formation of a $\mathrm{Cr} \mathrm{SDZ}$ at the interface.

The aforementioned results demonstrate that the lower impact toughness, higher UTS, and higher Vickers microhardness observed in the unaged $\mathrm{CF}-8$ steel are likely due to the presence of the carbides at the heterophase interfaces. Carbides were also observed at the heterophase interfaces of CF-8 steels aged to $4300 \mathrm{~h}$. We do not, however, observe $\mathrm{M}_{23} \mathrm{C}_{6}$ carbides in $\mathrm{CF}-3$ in the unaged condition or after aging to $4300 \mathrm{~h}$ at either operational or accelerated temperatures. These observations are in contrast to those in Refs. [5], [7], and [11], which only observed the carbide phase in $\mathrm{CF}-8$ aged at $\geq 400^{\circ} \mathrm{C}$. Thus, some studies have suggested that care must be taken in using $400{ }^{\circ} \mathrm{C}$ as an accelerated temperature in $\mathrm{CF}-8$, as it 
may not be representative of aging at operational temperatures. Our observations suggest, however, that contribution to embrittlement in $\mathrm{CF}-8$ by the $\mathrm{M}_{23} \mathrm{C}_{6}$ carbide can occur at both operational and accelerated aging temperatures since the carbide is present following solidification and solution treatment. It has been previously shown that the $\mathrm{M}_{23} \mathrm{C}_{6}$ carbide phase can form at the $\delta$-ferrite $/ \gamma$-austenite heterophase interfaces during the austenite-to-ferrite transformation in steels [50] and [51], and hence its presence can reasonably be expected in the unaged $\mathrm{CF}-8$ steels, as has been observed here.

\subsubsection{Atom Probe Tomography (APT): Spinodal Decomposition}

Incipient spinodal decomposition as illustrated by concentration fluctuations in the ferrite phase of the unaged CF-8 stainless steel was observed, Figs. 2(a) - (b). The ferrite phase of the unaged CF-3 stainless steel also exhibited incipient spinodal decomposition that was qualitatively similar to that observed in the CF-8 steel. Spinodal decomposition in the CDSS is described as phase separation of the $\delta$-ferrite phase into Fe-rich $\alpha$-domains (blue) and Cr-rich $\alpha$-domains (magenta). Our observations are similar to those in unaged model $\mathrm{Fe}-25 \mathrm{Cr}$ at. $\%$, $\mathrm{Fe}-30 \mathrm{Cr}$ at. \%, and $\mathrm{Fe}-36 \mathrm{Cr}$ at.\% binary alloys where the authors suggested that small amounts of decomposition may be present in the unaged ferrite phase due to the presence of positive $\mathrm{Cr}-$ $\mathrm{Cr}$ interactions at short distances when using radial distribution function (RDF) analysis [52]. Moreover, an earlier study by Pumphrey and Akhurst on an unaged CF-3 steel suggested that a small spinodal amplitude exists in the ferrite phase, but the wavelength was not determined [9]. Phase decomposition in the ferrite phase is seen to progress and the wavelength and amplitudes of the concentration fluctuations are observed to increase during aging to $4300 \mathrm{~h}$ as illustrated for the $\mathrm{CF}-8$ steel at $400{ }^{\circ} \mathrm{C}$, Figs. 10 (a) - (b). Additionally, a small G-phase precipitate is observed 
at an $\alpha$-domain/ $\alpha$-domain interface in Fig. 10(a) and is discussed below. The increase in wavelength and amplitude occurs at the two operational and the two accelerated aging temperatures in both steels.

The $\mathrm{Cr}$ wavelength and amplitude size distributions in the unaged $\mathrm{CF}-3$ and $\mathrm{CF}-8$ stainless steels are illustrated in Figs. 11(a) - (b) and Figs. 11(c) - (d), respectively. The binomial distribution of random wavelengths and amplitudes are superimposed on both figures and differ from the experimentally measured distributions. The quantity $\mathrm{MW}$ for $\mathrm{Cr}$ in $\mathrm{CF}-3$ is $1.9 \pm 0.2$ $\mathrm{nm}$ and $1.8 \pm 0.2 \mathrm{~nm}$ in $\mathrm{CF}-8$. The quantity $\mathrm{MA}$ for $\mathrm{Cr}$ in the $\mathrm{CF}-3$ steel is $4.4 \pm 0.2 \mathrm{~nm}$ and $4.4 \pm 0.2 \mathrm{~nm}$ in the $\mathrm{CF}-8$ steel. The MW values are slightly different than the mean wavelength determined by the ACF method, whereas the MA values exhibit greater difference with the amplitude determined by the LBM method, Figs. 12(a) - (b).

In order to account for the measured differences in local mean $\mathrm{Cr}$ concentration in the b.c.c. $\delta$-ferrite phase on the $\mathrm{Cr}$ spinodal decomposition amplitudes between the $\mathrm{CF}-3$ and $\mathrm{CF}-8$ steels, a ratio of normalized spinodal decomposition amplitudes, $A_{j}^{*}$, was calculated for an element $j, A_{j}^{*}=\left|A_{i}^{C F-8}\right| /\left|A_{i}^{C F-3}\right|=\left\{\left(A_{j}^{C F-8} / \bar{C}_{j}^{C F-8}\right)\right\} /\left\{A_{j}^{C F-3} / \bar{C}_{j}^{C F-3}\right\}$. The mean concentrations used in the equation for the quantity $A_{j}^{*}$ are from the proxigrams in Figs. 5(b) and 6(b) for $\mathrm{CF}-3$ and $\mathrm{CF}-8$, respectively. The quantity $A_{j}^{*}$ for $\mathrm{Cr}$ is 1.15 , which indicates the normalized $\mathrm{Cr}$ amplitude is greater in the $\mathrm{CF}-8$ steel. A decrease of the local mean $\mathrm{Cr}$ concentration in the ferrite phase may affect the $\mathrm{Cr}$ atomic mobility due to the concentration dependence of the interdiffusion coefficient [53], [54] in the Cahn-Hilliard equations and thus lead to different spinodal decomposition amplitudes in the steels. The small differences in nominal composition between the two steels suggest that incipient spinodal decomposition should be similar since the two steels would have a similar position in the miscibility gap of the 
phase diagram and hence the driving force for phase separation would be similar. The APT results demonstrate, however, that the normalized $\mathrm{Cr}$ amplitude in the unaged $\mathrm{CF}-8$ steel is greater than in the $\mathrm{CF}-3$ steel. This is possibly due to the presence of the $\mathrm{Cr}$-rich $\mathrm{M}_{23} \mathrm{C}_{6}$ carbide phase in $\mathrm{CF}-8$ and not $\mathrm{CF}-3$ that locally influences the $\mathrm{Cr}$ concentration in the ferrite phase by formation of the SDZ, as discussed above. In addition to the direct influence of the carbide phase on the measured differences in mechanical properties of the unaged steels, it is possible that the carbide also indirectly influences thermal embrittlement by affecting the $\mathrm{Cr}$ concentrations and amount of spinodal decomposition in the ferrite phase. The smaller differences in mechanical properties between the steels after aging to 4300 hours at accelerated temperatures when compared to operational temperatures suggest, however, that this effect may be limited to earlier stages of decomposition.

After aging to $4300 \mathrm{~h}$, the quantities MW and MA for Cr derived from wavelength and amplitude size distributions increase as illustrated in Figs. 12(a) - (f). The quantities MW and MA exhibit an increasing trend with increasing aging temperature and their values are greater for both accelerated temperatures when compared to the two operational temperatures for both steels. Additionally, only small differences are exhibited in the quantities MW and MA between the two steels at operational temperatures. The difference in values of these quantities, are however, slightly greater at accelerated temperatures and this may be caused by the influence of the G-phase precipitates on spinodal decomposition, as discussed below. The quantity MW exhibits slight differences when compared to the mean wavelength determined by the ACF method but both methods illustrate similar trends. The amplitude determined by the LBM method is consistently greater than when compared to the quantity MA but both values exhibit similar trends. Earlier studies of evaluating spinodal decomposition have illustrated quantitative 
differences between various methods of determining amplitude although they may exhibit similar trends [28] and [52]. In this study, the differences observed between the LBM method and the quantity MA is due to their underlying basis. The LBM method is categorized as a peakto-trough amplitude method, whereas the method presented in this study is a peak-to-mean composition amplitude method and thus the former will have quantitative values approximately twice as great as the latter. Furthermore, the LBM method is dependent on symmetry of the frequency distributions [52], and multicomponent alloys whose nominal or local compositions are not centered in the miscibility gap of the phase diagram, such as the $\mathrm{CF}-3$ and $\mathrm{CF}-8 \mathrm{CDSS}$ in this study, will exhibit asymmetry and thus the LBM method can produce greater variability in its results.

\subsubsection{Atom Probe Tomography (APT): G-phase Precipitates}

G-phase precipitates were not observed in the unaged specimens or the specimens aged at operational temperatures in both steels, as illustrated in Figs. 13(a) - (b). G-phase precipitates

are detected inside the decomposing ferrite phase of CF-3 aged at $360{ }^{\circ} \mathrm{C}$ and $400{ }^{\circ} \mathrm{C}$, and $\mathrm{CF}-8$ aged at $400{ }^{\circ} \mathrm{C}$. The $\mathrm{G}-$ phase is observed to form at the $\alpha / \alpha$ ' interfaces as illustrated in Figs. 10(a) - (b). The G-phase is a ternary intermetallic silicide that has a nominal stoichiometric composition of $\mathrm{Ni}_{16} \mathrm{Si}_{7} \mathrm{Ti}_{6}$ [55]. However, other metallic elements such as $\mathrm{Cr}$, Fe, and $\mathrm{Mn}$ can substitute for $\mathrm{Ni}$ and titanium (Ti) [6], [55], and [56]. As depicted in the example proxigram concentration profiles of $\mathrm{CF}-8$ aged at $400{ }^{\circ} \mathrm{C}$ in Fig. 14, the G-phase precipitates are enriched in $\mathrm{Ni}, \mathrm{Si}, \mathrm{Mn}$, and $\mathrm{Cu}$ but are depleted in $\mathrm{Fe}, \mathrm{Cr}$, and Mo and their compositional analysis is reported in Table 2. Copper is present as a residual element in the steels. The precipitates still contain measurable concentrations of $\mathrm{Fe}$ and $\mathrm{Cr}$ after aging to $4300 \mathrm{~h}$. It is possible that both 
elements diffuse out of the $\mathrm{G}$-phase while $\mathrm{Ni}, \mathrm{Si}$, and $\mathrm{Mn}$ diffuse into the $\mathrm{G}$-phase during further aging and the precipitates approach their equilibrium compositions. This is supported by the lower Fe and $\mathrm{Cr}$ concentrations and concomitantly higher Ni, Si, and Mn concentrations at 400 ${ }^{\circ} \mathrm{C}$ aging when compared to the slower kinetics at $360{ }^{\circ} \mathrm{C}$ aging for the $\mathrm{CF}-3$ steel. Trajectory aberrations and local magnifications effects may also influence the $\mathrm{Fe}$ and $\mathrm{Cr}$ concentrations in the G-phase. However, since the quantity $\langle R>$ is $>1 \mathrm{~nm}$, this will have limited effect on the core compositions [57]. Furthermore, recent studies of the G-phase in CF-3M illustrated that Fe and Cr concentrations decrease while $\mathrm{Ni}, \mathrm{Mn}, \mathrm{Si}$, and Mo concentrations increase in the precipitates with increasing aging time at accelerated temperatures [12] and [21]. The quantities $\langle R\rangle, N_{V}$, and $V_{f}$ of the $\mathrm{G}-$ phase precipitates in $\mathrm{CF}-3$ are greater than that of $\mathrm{CF}-8$ when aging at $400{ }^{\circ} \mathrm{C}$, Table 3, which suggests that the kinetics of $\mathrm{G}$-phase formation are slower in the latter. Further, the same morphological parameters are greater when aging at $400{ }^{\circ} \mathrm{C}$ than $360{ }^{\circ} \mathrm{C}$ in $\mathrm{CF}-3$ due to faster kinetics. Comparison of the precipitate radii, number density, and volume percentage results for $\mathrm{CF}-3$ at $360{ }^{\circ} \mathrm{C}$ and $400{ }^{\circ} \mathrm{C}$ in this study to $\mathrm{CF}-3 \mathrm{M}$ at $350{ }^{\circ} \mathrm{C}$ and $400{ }^{\circ} \mathrm{C}$ in Ref. [21] suggests that the kinetics of $\mathrm{G}$-phase formation is slower in $\mathrm{CF}-3$. These differences can be accounted for by variations in nominal composition, solution treatment, and heterogeneous distribution of the $\mathrm{G}-$ phase precipitates. The CF-3M steel in Ref. [21] had a greater nominal concentration of $\mathrm{Ni}$, which is known to accelerate $\mathrm{G}$-phase formation, and a greater nominal concentration of Mo, which is also known to promote G-phase precipitation [7].

\subsubsection{Comparison of Mechanical Property and Microstructural Evolution}

In general, the increasing Vickers microhardness, increasing UTS, and decreasing CVN impact toughness in both steels as illustrated in Figs. 3(a) - (f) corresponds to increasing values 
for the quantities MW and MA in both steels as illustrated in Figs. 12(a) - (f). Additionally, the greater values for MW and MA at accelerated temperatures compared to operational temperatures correspond in general to the greater degradation of the mechanical properties at the accelerated temperatures. As discussed above, the extent of spinodal decomposition increases with increasing temperature. In addition to the contribution by spinodal decomposition, G-phase precipitation at accelerated temperatures may influence embrittlement but its contribution has been debated in the literature and is not completely clear. The $\mathrm{G}$-phase was reported to contribute to embrittlement in Refs. [58], [59], and [60], whereas it was reported to have more limited contributions in Refs. [5], [11], and [12]. We measure little difference in the degree of mechanical property degradation at $360{ }^{\circ} \mathrm{C}$ aging between $\mathrm{CF}-3$ with $\mathrm{G}$-phase precipitation and CF-8 without G-phase precipitation thereby suggesting that its direct contribution is limited. It is possible, however that the G-phase could indirectly influence embrittlement by locally altering the Ni concentration, which would in turn influence kinetics of spinodal decomposition in the ferrite phase as suggested in Refs. [6] and [11].

\section{Conclusion}

The effect of aging temperatures on the mechanical property degradation and phase decomposition in $\mathrm{CF}-3$ and $\mathrm{CF}-8$ steels was studied experimentally. The $\delta$-ferrite $/ \gamma$-austenite heterophase interface, $\mathrm{M}_{23} \mathrm{C}_{6}$ carbide, spinodal decomposition, and $\mathrm{G}$-phase precipitation were analyzed in unaged and aged steels. The steels were aged at operational temperatures of $280{ }^{\circ} \mathrm{C}$ and $320{ }^{\circ} \mathrm{C}$ and accelerated temperatures of $360{ }^{\circ} \mathrm{C}$ and $400{ }^{\circ} \mathrm{C}$ for $4300 \mathrm{~h}$. This investigation resulted in the following findings: 
(1) Compared to the unaged $\mathrm{CF}-3$ steel, the unaged $\mathrm{CF}-8$ steel has higher UTS and Vickers microhardness values, but lower CVN impact toughness values. The CF-3 steel has a UTS of $530 \mathrm{MPa}$, Vickers microhardness of $151.8 \pm 4.6 \mathrm{HV} 500 \mathrm{~g}$, and impact toughness of $392 \pm 14 \mathrm{~J}$. The CF-8 steel has a UTS of $570 \mathrm{MPa}$, Vickers microhardness of $165.8 \pm 5.8 \mathrm{HV} 500 \mathrm{~g}$, and impact toughness of $317 \pm 80 \mathrm{~J}$.

(2) Selected area electron diffraction (SAED) observations illustrated that a $\mathrm{M}_{23} \mathrm{C}_{6}$ carbide is present at the heterophase interphases of the unaged $\mathrm{CF}-8$ steel but not the unaged $\mathrm{CF}-3$ steel, and it is not present in the interior of the grains in either steel. The carbide phase is not observed in the $\mathrm{CF}-3$ after aging to 4300 h. The $\mathrm{M}_{23} \mathrm{C}_{6}$ carbide has an f.c.c. crystal structure with a lattice parameter of $1.109 \mathrm{~nm}$. It has a composition of $32.5 \pm 2.1$ at.\% Fe, $49.2 \pm 1.5$ at.\% Cr, $11.9 \pm 1.2$ at.\% C, $2.0 \pm 0.4$ at.\% Mo, $2.1 \pm 0.7$ at.\% Ni, $1.1 \pm 0.2$ at.\% Mn, and $0.65 \pm 0.14$ at.\% Si. A Cr solute depleted zone (SDZ) is present in the ferrite phase of the unaged $\mathrm{CF}-8$ but not the unaged $\mathrm{CF}-3$. In the ferrite phase, the $\mathrm{Cr}$ concentration was 28.7 at. $\%$ in the $\mathrm{CF}-3$ steel and 24.9 at. $\%$ in the $\mathrm{CF}-8$ steel with a carbide present at the heterophase interface.

(3) Incipient spinodal decomposition was observed in the b.c.c. $\delta$-ferrite phase of the unaged CF-3 and CF-8 steels. The wavelength and amplitude size distributions differed from binomial distribution of random wavelengths and amplitudes. The spinodal domains in CF-3 steel have a mean wavelength (MW) of $1.8 \pm 0.2 \mathrm{~nm}$ and a mean amplitude (MA) of $4.4 \pm 0.2$ at.\% $\mathrm{Cr}$, whereas the domains in CF-8 steel have a MW of $1.9 \pm 0.2 \mathrm{~nm}$ and a MA of $4.4 \pm 0.2$ at. $\% \mathrm{Cr}$. (4) After aging to $4300 \mathrm{~h}$ spinodal decomposition progresses and the quantities MW and MA increase for both steels at the two operational and two accelerated temperatures. These quantities are greater in the steels aged at accelerated temperatures than operational temperatures. Concomitantly, the Vickers microhardness and UTS increase while the CVN impact toughness 
values decrease for both steels. The mechanical property degradation is greater at accelerated temperatures than operational temperatures.

(5) G-phase precipitates were observed in $\mathrm{CF}-3$ aged at $360{ }^{\circ} \mathrm{C}$ and both steels aged at 400 ${ }^{\circ} \mathrm{C}$. The radius, number density, and volume percentage (fraction) of G-phase in $\mathrm{CF}-3$ are greater than those in $\mathrm{CF}-8$.The radius, number density, and volume percentage is $1.1 \pm 0.4 \mathrm{~nm}$, $9.5 \times 10^{22} \pm 4.1 \times 10^{22}$ ppts. $/ \mathrm{m}^{3}$, and $0.1 \pm 0.02 \%$, respectively, for the $\mathrm{CF}-3$ steel aged at $360{ }^{\circ} \mathrm{C}$; and is $2.0 \pm 0.2 \mathrm{~nm}, 1.7 \times 10^{23} \pm 4.3 \times 10^{22}$ ppts. $/ \mathrm{m}^{3}$, and $0.8 \pm 0.02 \%$, respectively, for the $\mathrm{CF}-3$ steel aged at $400{ }^{\circ} \mathrm{C}$. The same parameters are $1.6 \pm 0.3 \mathrm{~nm}, 1.3 \times$ $10^{23} \pm 3.3 \times 10^{22}$ ppts. $/ \mathrm{m}^{3}$, and $0.4 \pm 0.02 \%$, respectively, in the $\mathrm{CF}-8$ steel aged at $400{ }^{\circ} \mathrm{C}$. 


\section{Acknowledgements}

This work is supported by the Department of Energy - Nuclear Energy University Program (DOE-NEUP), contract number DE-NE0000724; Dr. Jeremy T. Busby, Oak Ridge National

Laboratory (ORNL), technical monitor. A part of this research was performed using the Environmental Molecular Sciences Laboratory (EMSL), a DOE Office of Science User Facility sponsored by the Office of Biological and Environmental Research and located at Pacific Northwest National Laboratory (PNNL). We would like to thank Mr. Michael Perna, University of Maryland (UMD), for machining all specimen blanks and mechanical property test specimens; Professor Isabel Lloyd, UMD, for use of the Vickers microhardness tester; and Dr. Robert Bonenberger, UMD, for his assistance with the equipment in the Modern Engineering Materials Instructional Laboratory (MEMIL). Ms. Sarah Mburu is partially supported by the National Science Foundation (NSF) Louis Stokes Alliances for Minority Participation (LSAMP) under Grant No. 0833018. Mr. Schwarm would like to acknowledge the Department of Energy: Office of Nuclear Energy (DOE-NE) Integrated University Program (IUP) fellowship program for support. We acknowledge the support of the Maryland NanoCenter and its AIMLab and FabLab. 


\section{List of Tables}

Table 1. Nominal composition (wt.\%) of the $\mathrm{CF}-3$ and $\mathrm{CF}-8$ cast duplex stainless steels (CDSS) as measured by optical emission spectroscopy (OES).

\begin{tabular}{ccccccccc}
\hline & & $\mathbf{7}$ Composition (wt.\%) \\
\cline { 3 - 9 } Steel & & $\mathbf{F e}$ & $\mathbf{C r}$ & $\mathbf{N i}$ & $\mathbf{S i}_{\max }$ & $\mathbf{M n}_{\max }$ & $\mathbf{M o}_{\max }$ & $\mathbf{C}_{\max }$ \\
\hline CF-3 & ASTM A351 & Balance & $17.0-21.0$ & $8.0-12.0$ & 2.00 & 1.50 & 0.50 & 0.03 \\
\hline & Unaged & 69.52 & 19.69 & 8.40 & 0.98 & 1.07 & 0.28 & 0.02 \\
\hline CF-8 & ASTM A351 & Balance & $18.0-21.0$ & $8.0-11.0$ & 2.00 & 1.50 & 0.50 & 0.08 \\
\hline & Unaged & 69.44 & 19.85 & 8.30 & 0.97 & 0.99 & 0.35 & 0.06 \\
\hline
\end{tabular}

Table 2. Composition of G-phase precipitates in CF-3 and CF- 8 after $4300 \mathrm{~h}$ aging as measured by atom probe tomography (APT).

\begin{tabular}{|l|c|c|c|c|c|c|c|c|}
\hline & & \multicolumn{7}{|c|}{ Composition (at.\%) } \\
\hline & & $\mathbf{F e}$ & $\mathbf{C r}$ & $\mathbf{N i}$ & $\mathbf{S i}$ & $\mathbf{M n}$ & $\mathbf{C u}$ & $\mathbf{M o}$ \\
\hline $\mathbf{C F}-\mathbf{3}$ & $\mathbf{3 6 0}^{\circ} \mathbf{C}$ & 54.19 & 19.07 & 17.21 & 3.72 & 4.19 & 0.93 & 0.23 \\
\hline & $\mathbf{4 0 0}^{\circ} \mathbf{C}$ & 40.14 & 15.05 & 22.23 & 7.44 & 7.18 & 6.83 & 0.61 \\
\hline $\mathbf{C F}-\mathbf{8}$ & $\mathbf{3 6 0}^{\circ} \mathbf{C}$ & ND & ND & ND & ND & ND & ND & ND \\
\hline & $\mathbf{4 0 0}^{\circ} \mathbf{C}$ & 45.60 & 13.88 & 20.39 & 7.21 & 7.58 & 4.14 & 0.23 \\
\hline
\end{tabular}

$\mathrm{ND}=$ Not detected.

Table 3. Mean radius, $\left\langle R>\right.$, number density, $N_{V}$, and volume percentage, $V_{f}$, of G-phase precipitates in $\mathrm{CF}-3$ and $\mathrm{CF}-8$ after $4300 \mathrm{~h}$ aging as measured by atom probe tomography (APT).

\begin{tabular}{|c|c|c|c|c|}
\hline & & \multicolumn{3}{|c|}{ Parameters } \\
\hline & & $\langle\boldsymbol{R}\rangle(\mathbf{n m})$ & $\boldsymbol{N}_{\boldsymbol{V}}$ (ppt./m $\left.\mathbf{m}^{3}\right)$ & $\boldsymbol{V}_{\boldsymbol{f}}(\boldsymbol{\%})$ \\
\hline $\mathbf{C F}-\mathbf{3}$ & $\mathbf{3 6 0}^{\circ} \mathbf{C}$ & $1.1 \pm 0.4$ & $9.5 \times 10^{22} \pm 4.1 \times 10^{22}$ & $0.1 \pm 0.02$ \\
\hline & $\mathbf{4 0 0}^{\circ} \mathbf{C}$ & $2.0 \pm 0.2$ & $1.7 \times 10^{23} \pm 4.3 \times 10^{22}$ & $0.8 \pm 0.02$ \\
\hline $\mathbf{C F}-8$ & $\mathbf{3 6 0}^{\circ} \mathbf{C}$ & $\mathrm{ND}$ & $\mathrm{ND}$ & $\mathrm{ND}$ \\
\hline & $\mathbf{4 0 0}^{\circ} \mathbf{C}$ & $1.6 \pm 0.3$ & $1.3 \times 10^{23} \pm 3.3 \times 10^{22}$ & $0.4 \pm 0.02$ \\
\hline
\end{tabular}

$\mathrm{ND}=$ Not detected. 


\section{List of Figure Captions}

Graphical Abstract. Understanding relationships between microstructure and mechanical behavior in cast duplex stainless steels across multiple length scales.

Figure 1. (a) Site-specific lift-out of an APT specimen tip at an example $\delta$-ferrite $/ \gamma$-austenite heterophase interface (dashed yellow line) using a SEM/FIB instrument. (b) - (e) series of images illustrating the annular milling of a specimen into a needle morphology with sequentially decreasing tip diameter necessary for APT analysis.

Figure 2. (a) An example region of interest (ROI) illustrating the compositional heterogeneity of alternating Fe-rich $\alpha$-domains (blue) and Cr-rich $\alpha$ '-domains (magenta) with (b) corresponding $\mathrm{Fe}$ and $\mathrm{Cr}$ concentration profiles. The individual fluctuation peaks in the $\mathrm{Fe}$ and $\mathrm{Cr}$ profiles are numbered and an example wavelength, $\lambda$, and amplitude, $\mathrm{A}$, are depicted for the Fe profile. The mean of the $\mathrm{Fe}$ and $\mathrm{Cr}$ concentrations are superimposed in the plot as solid horizontal lines.

Figure 3. Mechanical properties as a function aging time at the unaged (green diamonds) and $280{ }^{\circ} \mathrm{C}$ (red circles), $320^{\circ} \mathrm{C}$ (blue squares), $360^{\circ} \mathrm{C}$ (purple triangles), and $400{ }^{\circ} \mathrm{C}$ (orange stars) aging temperatures: Vickers Microhardness of (a) $\mathrm{CF}-3$ and (d) $\mathrm{CF}-8$, ultimate tensile strength (UTS) of (b) CF-3 and (e) CF-8, and Charpy V-notch (CVN) impact toughness of (c) CF-3 and (f) $\mathrm{CF}-8$. Solid symbols indicate $\mathrm{CF}-3$ while open symbols indicate $\mathrm{CF}-8$. Trend lines from the unaged data to the aged data are drawn with corresponding colors. The operational temperatures $\left(280{ }^{\circ} \mathrm{C}\right.$ and $\left.320^{\circ} \mathrm{C}\right)$ are solid lines, while the accelerated temperatures $\left(360^{\circ} \mathrm{C}\right.$ and $\left.400{ }^{\circ} \mathrm{C}\right)$ are dashed lines.

Figure 4. Optical micrograph of the unaged $\mathrm{CF}-3$ stainless steel microstructure illustrating the $\gamma$-austenite phase (light color) and islands of $\delta$-ferrite phase (dark color).

Figure 5. (a) APT reconstruction of unaged $\mathrm{CF}-3$ with $61 \mathrm{~nm} \times 64 \mathrm{~nm}$ dimensions illustrating the $\delta$-ferrite/ $\gamma$-austenite heterophase interface. $0 \%$ of the $\mathrm{Fe}$ (blue) ions, $30 \%$ of the $\mathrm{Cr}$ ions (magenta), and 100\% of $\mathrm{Ni}$ (green), Mn (mustard), Si (gray), Mo (red), and C (black) are depicted for clarity. (b) Proximity histogram concentration profiles for $\mathrm{Fe}$ (blue circles), $\mathrm{Ni}$ (green squares), Mn (mustard stars), Cr (magenta triangles), Si (gray diamonds), Mo (red asterisks), and C (black left-triangles) using a 4.5 at. $\% \mathrm{Ni}$ isoconcentration surface. The $\pm 2 \sigma$ error bars are based on counting statistics. For the major elements, the error bars are smaller than the marker size.

Figure 6. (a) APT reconstruction of unaged $\mathrm{CF}-8$ with $94 \mathrm{~nm} \times 61 \mathrm{~nm}$ dimensions illustrating the $\delta$-ferrite/ $\gamma$-austenite heterophase interface. $0 \%$ of the $\mathrm{Fe}$ (blue) ions, $30 \%$ of the $\mathrm{Cr}$ ions (magenta), and 100\% of Ni (green), Mn (mustard), Si (gray), Mo (red), and C (black) are depicted for clarity. (b) Proximity histogram concentration profiles for $\mathrm{Fe}$ (blue circles), $\mathrm{Ni}$ (green squares), Mn (mustard stars), Cr (magenta triangles), $\mathrm{Si}$ (gray diamonds), Mo (red asterisks), and C (black left-triangles) using a 4.5 at. $\% \mathrm{Ni}$ isoconcentration surface. The $\pm 2 \sigma$ error bars are based on counting statistics. For the major elements, the error bars are smaller than the marker size. 
Figure 7. (a) An SEM image of an APT specimen tip illustrating $\mathrm{M}_{23} \mathrm{C}_{6}$ carbides interspersed along the $\delta$-ferrite $/ \gamma$-austenite heterophase interface in $\mathrm{CF}-8$. (b) APT reconstruction of the same unaged $\mathrm{CF}-8$ data set as in Fig. 5(a), with a 2.5 at.\% $\mathrm{C}$ isoconcentration surface to better visualize the $\mathrm{M}_{23} \mathrm{C}_{6}$ carbide phase. Reconstruction dimensions: $94 \mathrm{~nm} \times 61 \mathrm{~nm}$. $0 \%$ of the Fe (blue) ions, $30 \%$ of the $\mathrm{Cr}$ ions (magenta), and $100 \%$ of Ni (green), Mn (mustard), Si (gray), Mo (red), and C (black) are depicted for clarity. (c) Rotated view of Fig. 6(b) to show that the carbide intersects the edge of the reconstruction volume. (d) One-dimensional (1D) concentration profiles using a $1 \mathrm{~nm} \times 1 \mathrm{~nm} \times 30 \mathrm{~nm}$ rectangular region of interest (ROI) seen in Fig. 6(b) for $\mathrm{Fe}$ (blue circles), Ni (green squares), Mn (mustard stars), Cr (magenta triangles), Si (gray diamonds), Mo (red asterisks), and $\mathrm{C}$ (black left-triangles) across the carbide phase. The $\pm 2 \sigma$ error bars are based on counting statistics.

Figure 8. Conventional TEM images of the $\delta$-ferrite $/ \gamma$-austenite heterophase interface in (a) $\mathrm{CF}-$ 3 and (b) $\mathrm{CF}-8$ duplex stainless steels with (insets) selected area electron diffraction (SAED) patterns along a f.c.c. $\gamma$-austenite [001] zone axis.

Figure 9. (a) - (b) Conventional TEM images of an $\mathrm{M}_{23} \mathrm{C}_{6}$ carbide observed at the heterophase interface in $\mathrm{CF}-8$ duplex stainless steel with (c) associated SAED pattern of the f.c.c. carbide along the $\gamma$-austenite/ $\mathrm{M}_{23} \mathrm{C}_{6}[\overline{3} 01]$ zone axis and (d) TEM-EDS scan results of element concentrations taken along a $430 \mathrm{~nm}$ line across the $\mathrm{M}_{23} \mathrm{C}_{6}$ carbide from the $\delta$-ferrite phase to the $\gamma$-austenite phase along the dashed arrow in Fig. 9(b).

Figure 10. (a) An example region of interest (ROI) illustrating the compositional heterogeneity of alternating Fe-rich $\alpha$-domains (blue), Cr-rich $\alpha$-domains (magenta), and a Ni-rich $\mathrm{G}$-phase precipitate (green) with (b) corresponding $\mathrm{Fe}, \mathrm{Cr}$, and Ni concentration profiles for $\mathrm{CF}-8$ specimen aged to $4300 \mathrm{~h}$ at $400{ }^{\circ} \mathrm{C}$. The $\mathrm{Fe}$ and $\mathrm{Cr}$ mean concentrations are superimposed in the plot as solid horizontal lines.

Figure 11. Distribution histograms of $\mathrm{Cr}$ with superimposed random binomial distribution curves for unaged (a) $\mathrm{CF}-3$ wavelength, (b) $\mathrm{CF}-8$ wavelength, (c) $\mathrm{CF}-3$ amplitude, and (d) $\mathrm{CF}-8$ amplitude.

Figure 12. (a) The mean wavelength (MW) and (b) mean amplitude (MA) values of CF-3 (solid symbols) and $\mathrm{CF}-8$ (open symbols) are plotted as a function of aging temperatures: unaged (diamonds) and specimens aged to $4300 \mathrm{~h}$ at $280{ }^{\circ} \mathrm{C}$ (circles), $320^{\circ} \mathrm{C}$ (squares), $360{ }^{\circ} \mathrm{C}$ (triangles), and $400{ }^{\circ} \mathrm{C}$ (stars). The $\mathrm{MW}$ values (black) are compared to the auto correlation function (ACF) method wavelengths (blue) and the MA values (black) are compared to the Langer Bar-on Miller (LBM) method amplitudes (red). The ACF and LBM method values are staggered to the right of the MW and MA values by $5{ }^{\circ} \mathrm{C}$ for clarity. The mean wavelength (MW) of (c) $\mathrm{CF}-3$ and (e) $\mathrm{CF}-8$ and the mean amplitude (MA) of (d) $\mathrm{CF}-3$ and (f) $\mathrm{CF}-8$ are plotted as a function of aging time. Solid symbols indicate $\mathrm{CF}-3$ while open symbols indicate $\mathrm{CF}-8$. Trend lines from the unaged data to the aged data are drawn with corresponding colors. The operational temperatures $\left(280^{\circ} \mathrm{C}\right.$ and $\left.320^{\circ} \mathrm{C}\right)$ are solid lines, while the accelerated temperatures $\left(360{ }^{\circ} \mathrm{C}\right.$ and $400{ }^{\circ} \mathrm{C}$ ) are dashed lines. 
Figure 13. (a) Series of APT reconstructions illustrating G-phase precipitates in the decomposing $\delta$-ferrite phase delineated by 6.5 at. $\% \mathrm{Ni}$ (green) isoconcentration surfaces in unaged and $4300 \mathrm{~h}$ aged CF-3 specimens. (b) Series of G-phase precipitates delineated by 6.5 at. $\% \mathrm{Ni}$ (green) isoconcentration surfaces in unaged and $4300 \mathrm{~h}$ aged $\mathrm{CF}-8$ specimens. The $\mathrm{G}-$ phase precipitates are only observed in $\mathrm{CF}-3$ aged at $360{ }^{\circ} \mathrm{C}$ and $400{ }^{\circ} \mathrm{C}$, and $\mathrm{CF}-8$ aged at 400 ${ }^{\circ} \mathrm{C}$. The $\gamma$-austenite phase has a Ni concentration greater than the 6.5 at. $\%$ threshold and thus is displayed as large green isosurfaces. Only displaying $10 \%$ of the Ni (green) atoms for clarity.

Figure 14. Example $\mathrm{G}$-phase precipitate proximity histogram concentration profiles in $\mathrm{CF}-8$ aged to $4300 \mathrm{~h}$ at $400{ }^{\circ} \mathrm{C}$ for Fe (blue circles), Ni (green squares), Mn (mustard stars), $\mathrm{Cr}$ (magenta triangles), $\mathrm{Si}$ (gray diamonds), $\mathrm{Mo}$ (red asterisks), and $\mathrm{Cu}$ (orange right-triangles) using a 6.5 at.\% Ni isoconcentration surface. The $\pm 2 \sigma$ error bars are based on counting statistics. For the major elements, the error bars are smaller than the marker size. 
List of Figures

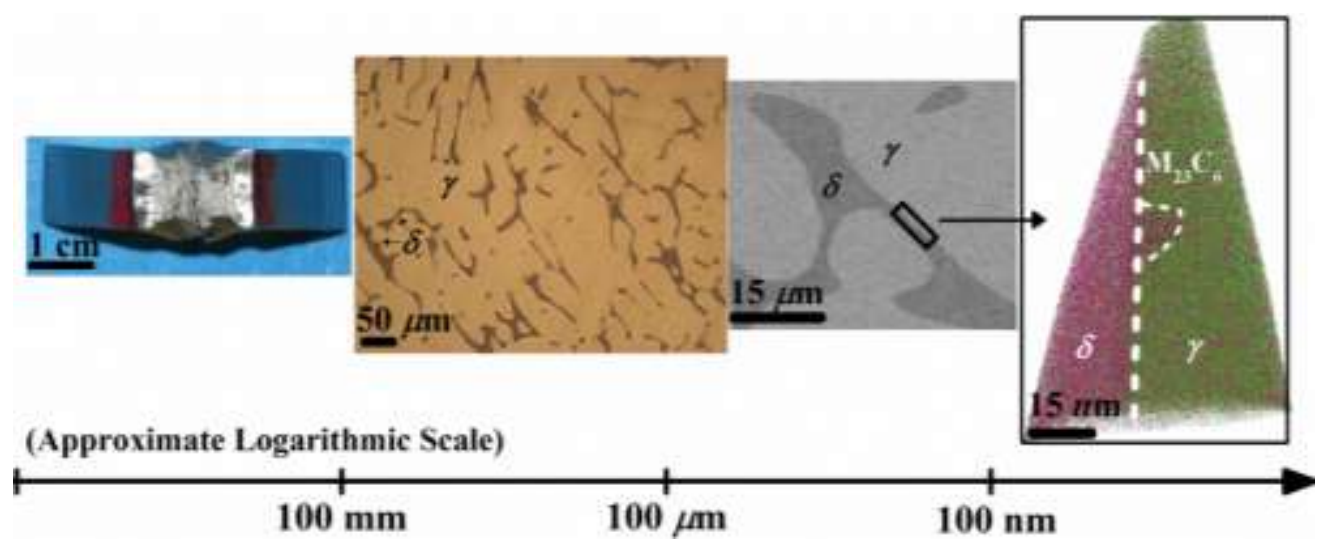

Graphical Abstract 


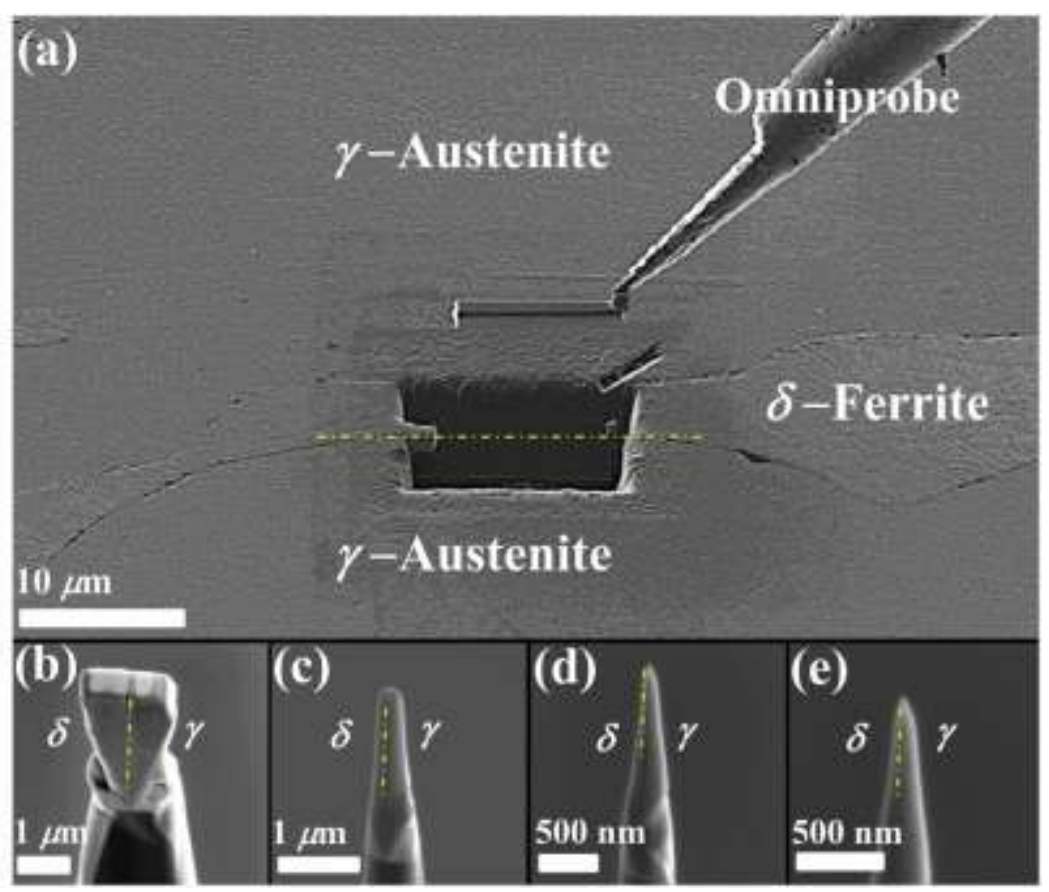

Figure 1 


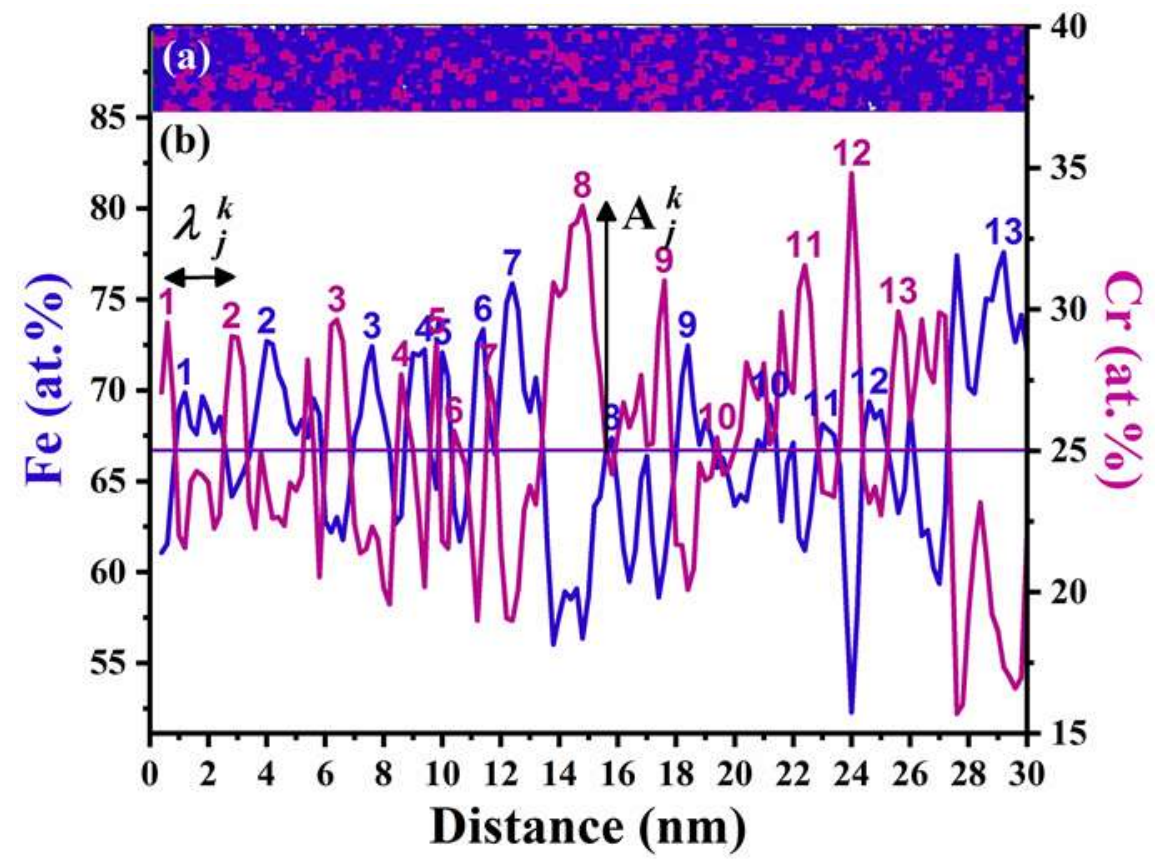

Figure 2 

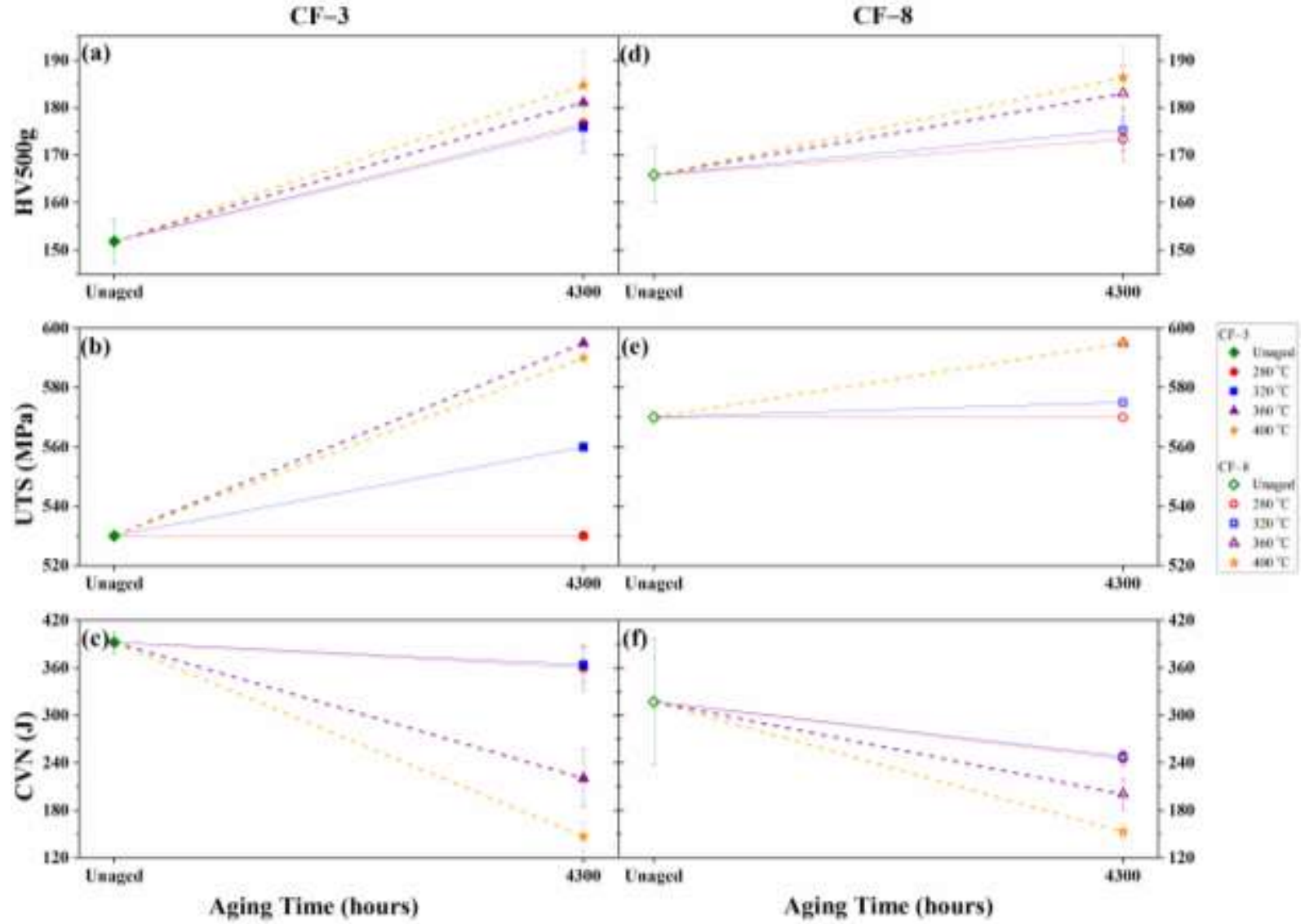

Figure 3 


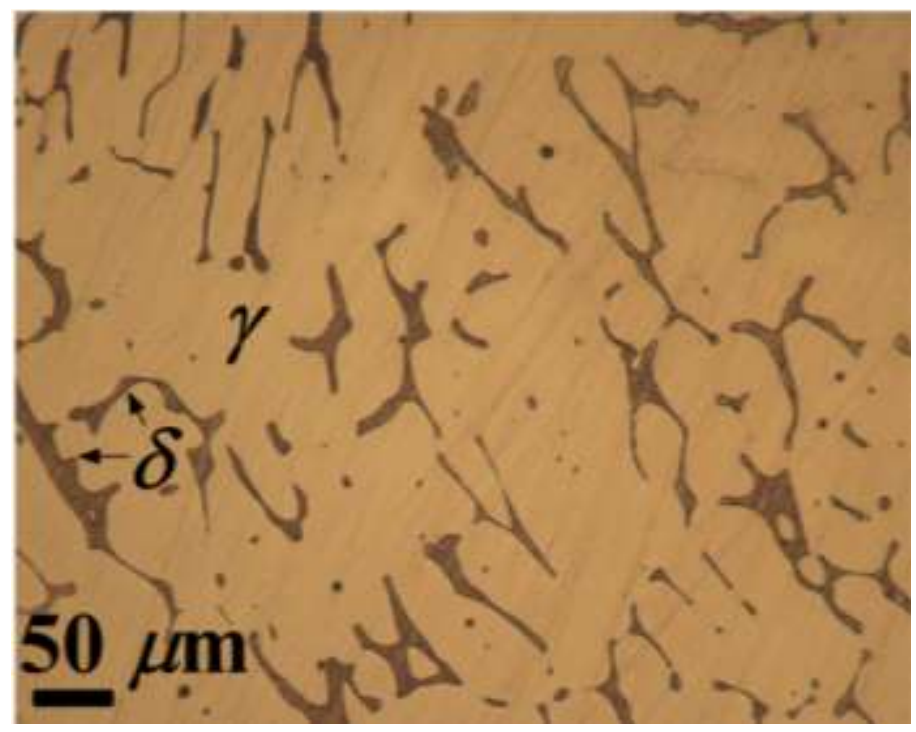

Figure 4 


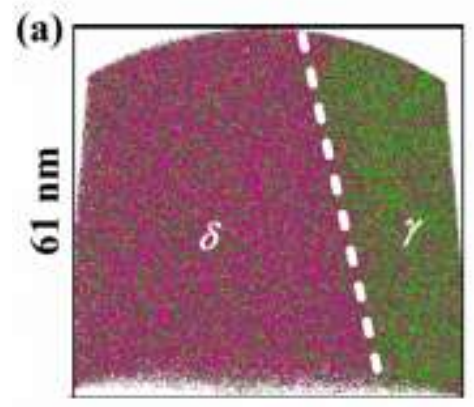

$64 \mathrm{~nm}$

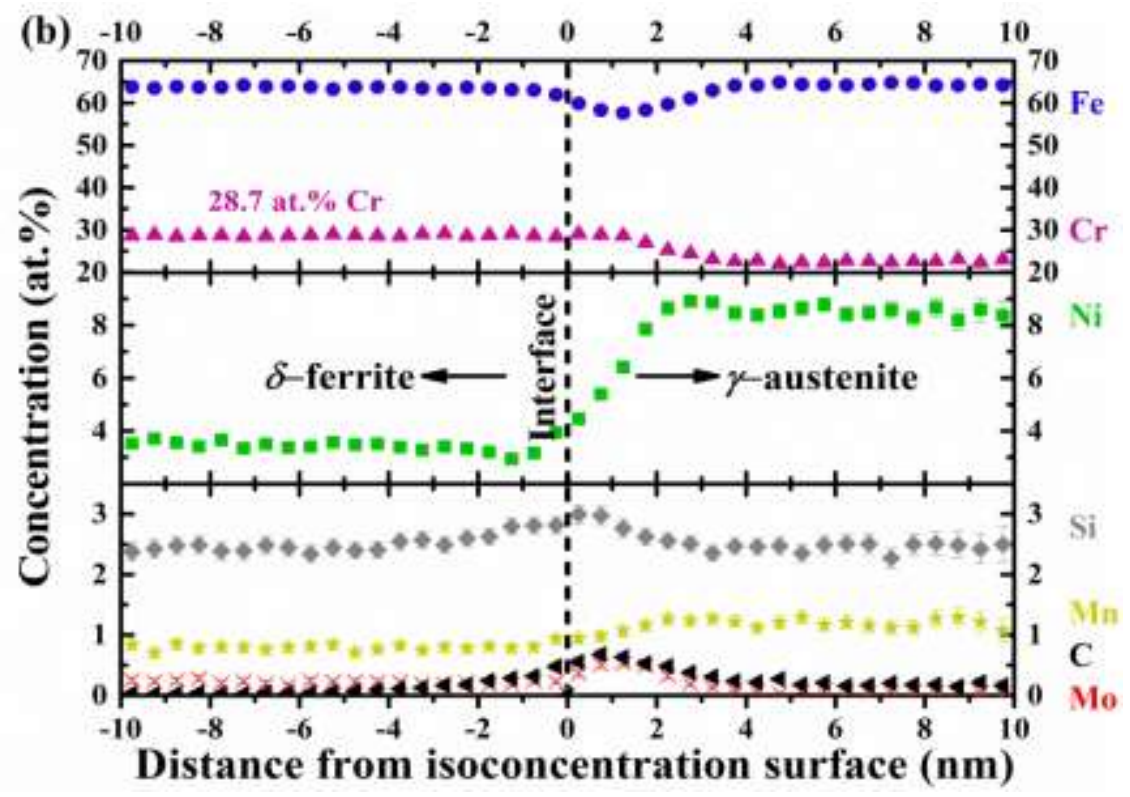

Figure 5 
(a)

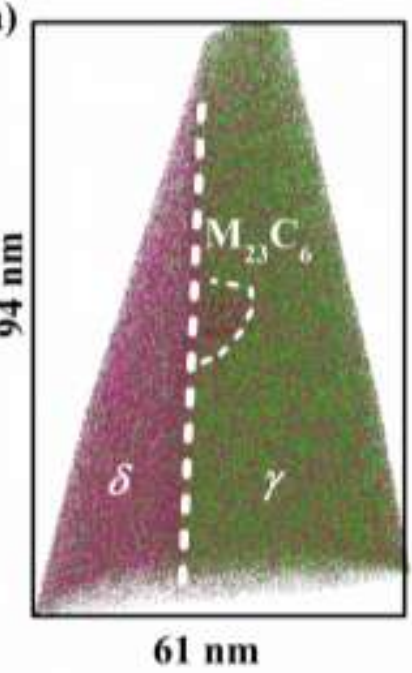

(b)

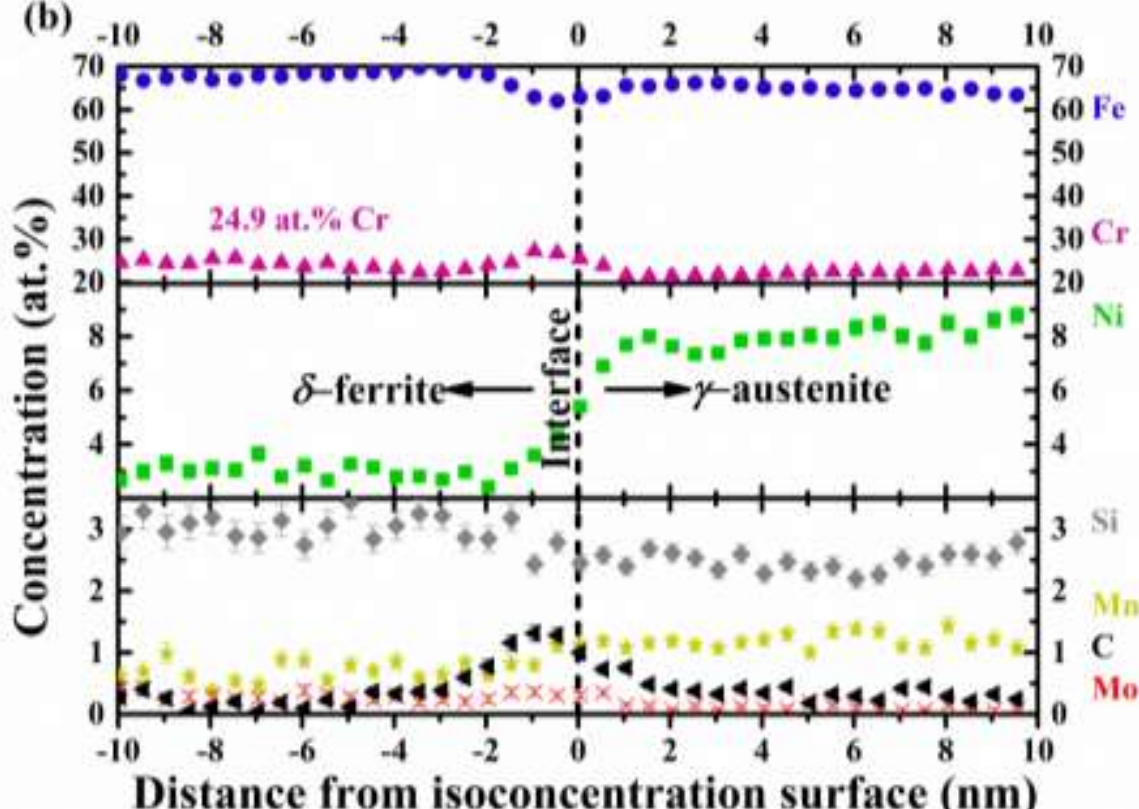

Distance from isoconcentration surface (nm)

Figure 6 
(a)

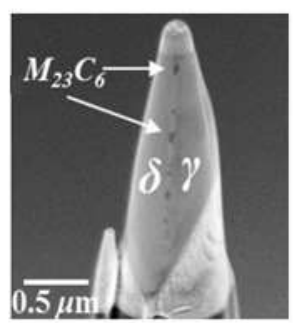

(b)

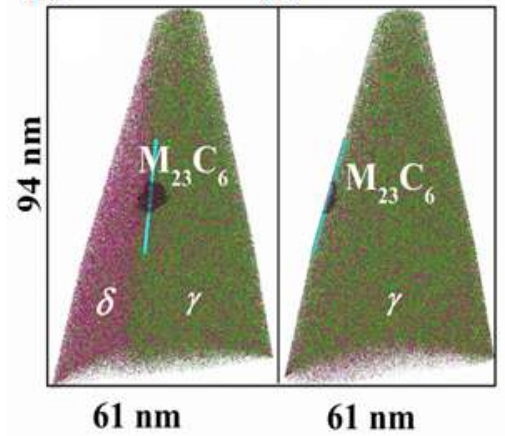

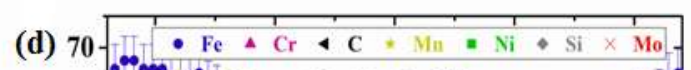

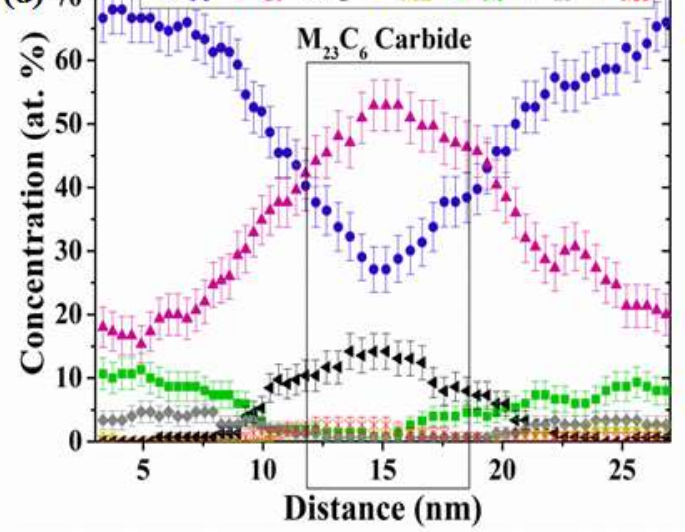

Figure 7 


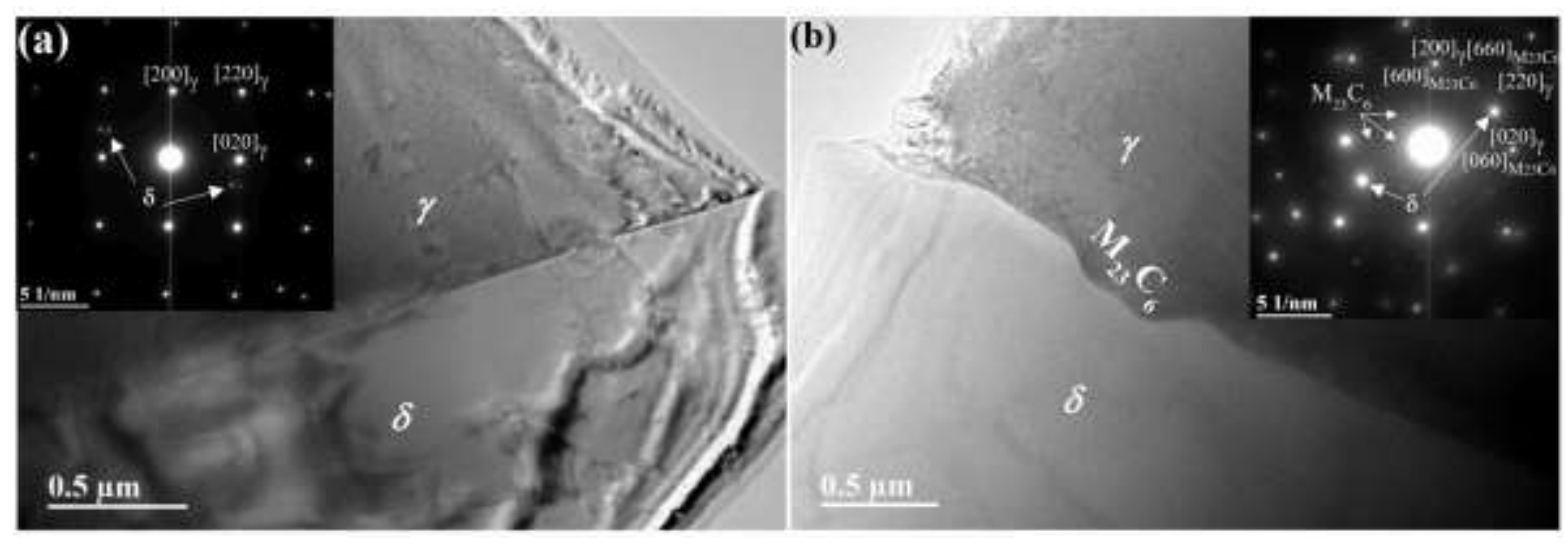

Figure 8 


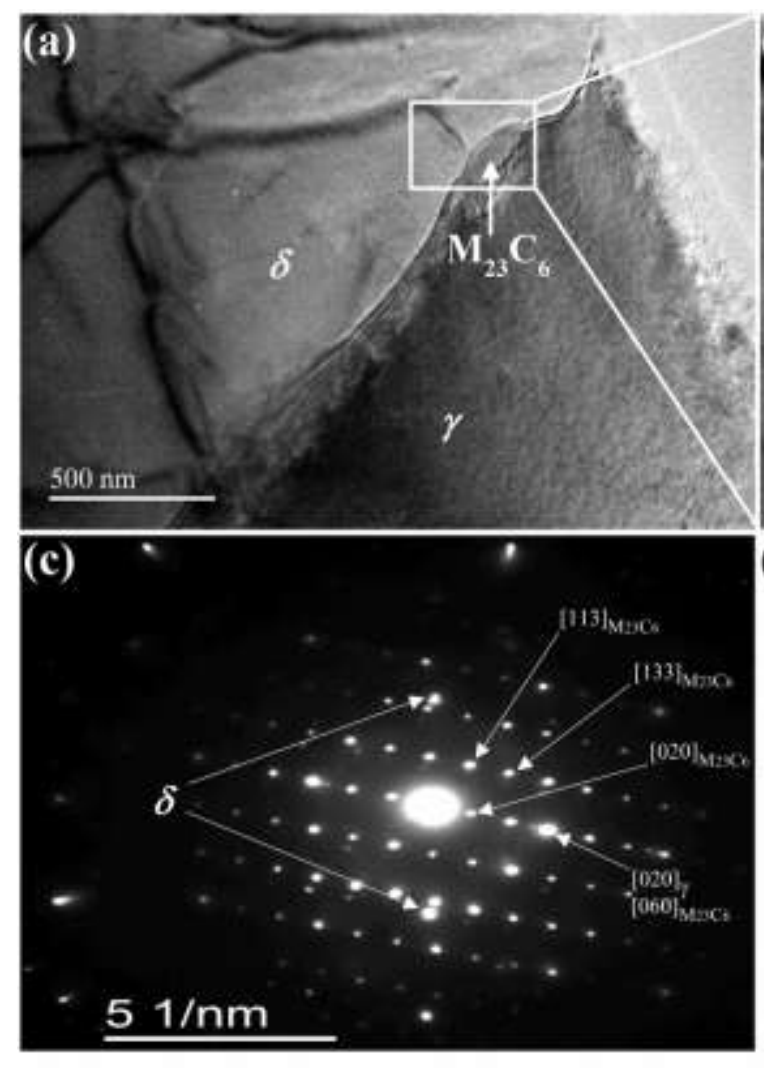

Figure 9
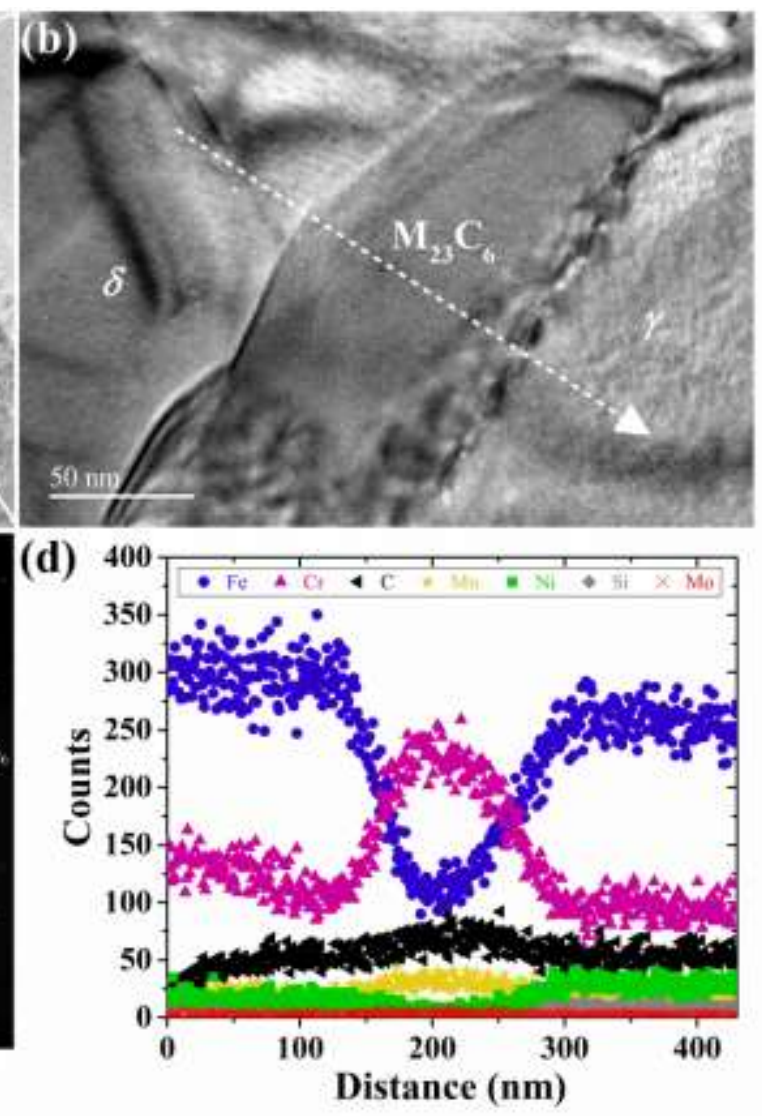


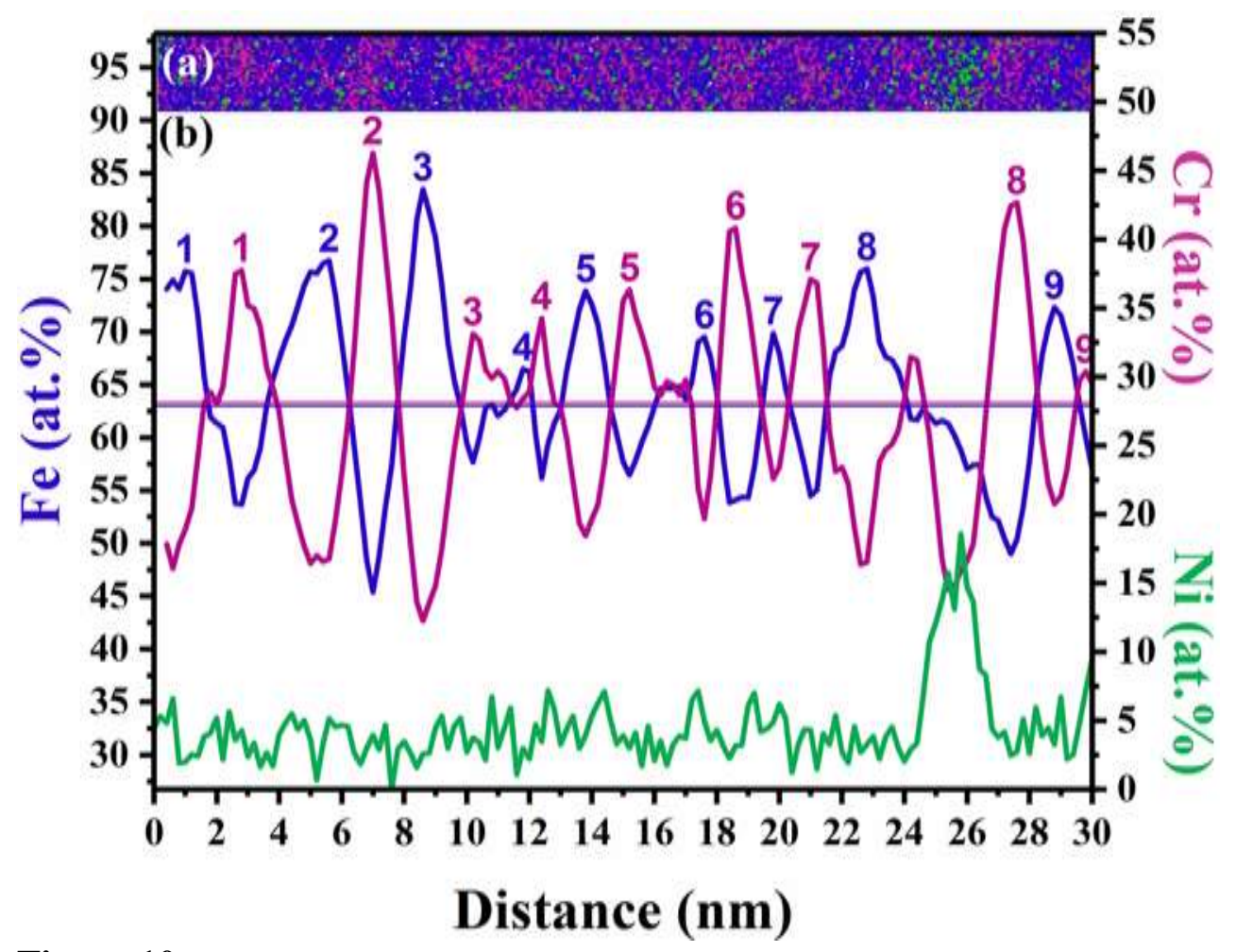

Figure 10 


\section{$\mathrm{CF}-3$ (no $\mathrm{M}_{23} \mathrm{C}_{6}$ carbide)}

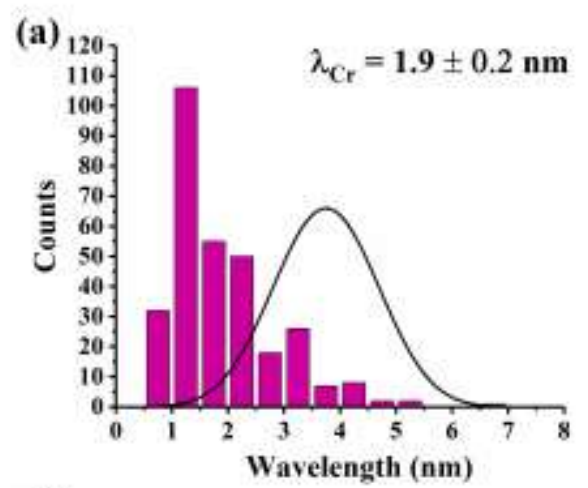

(c)

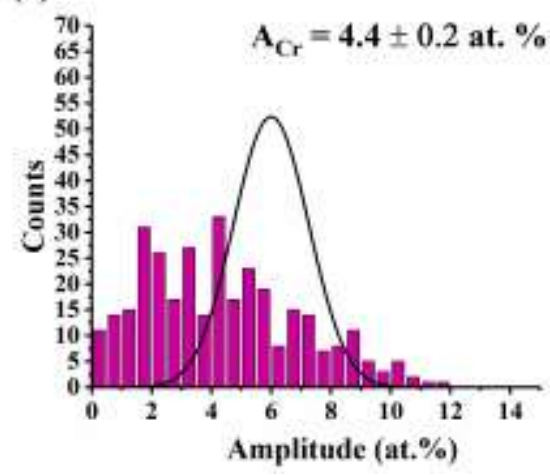

CF-8 (with $\mathrm{M}_{23} \mathrm{C}_{6}$ carbide)

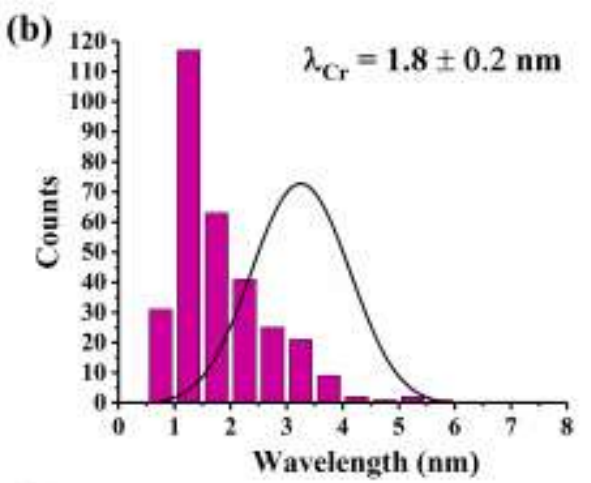

(d)

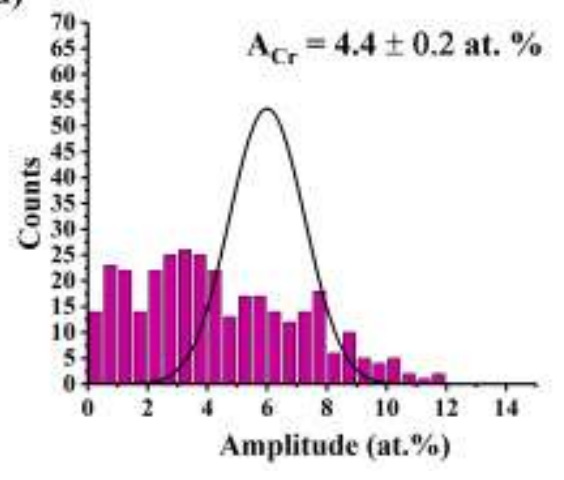

Figure 11 

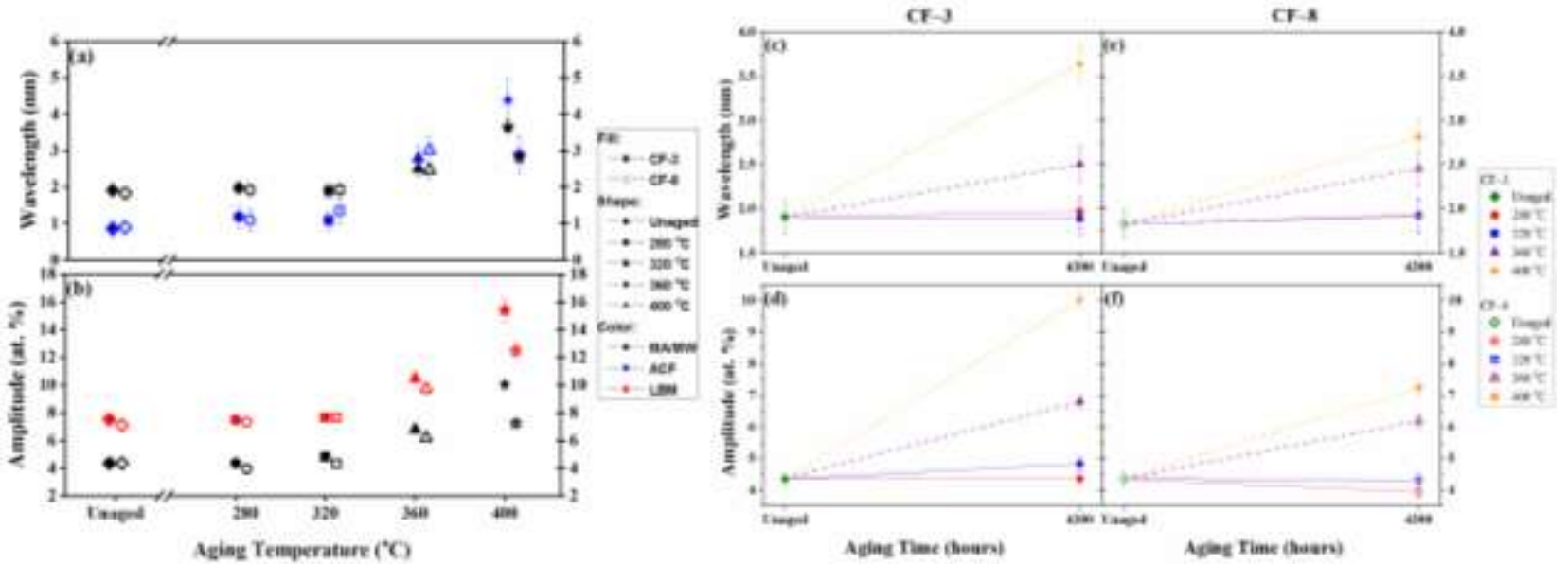

Figure 12 
(a) $\mathrm{CF}-3$

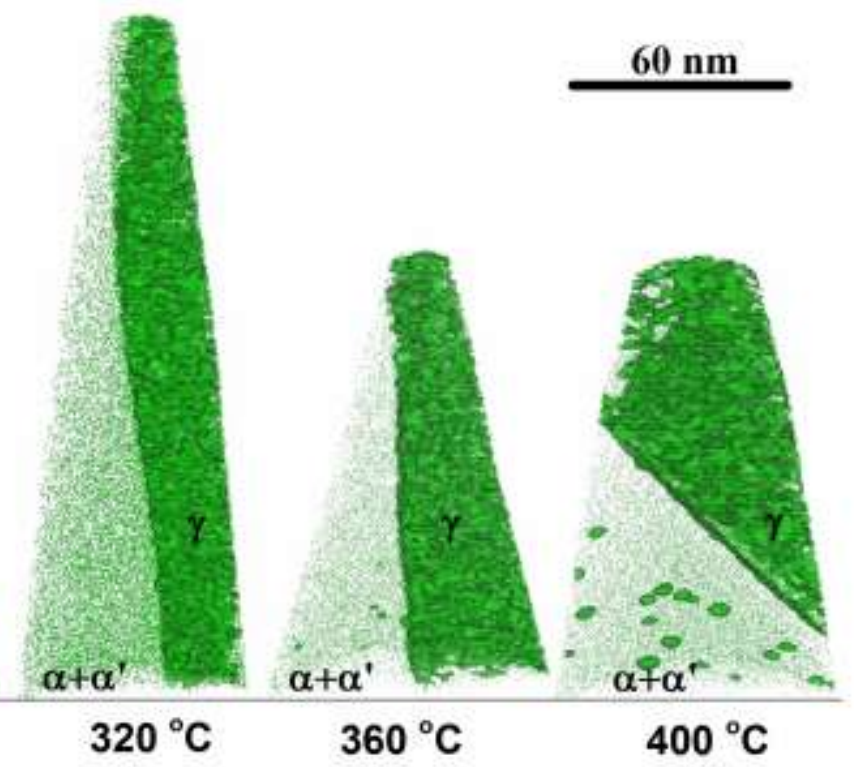

(b) $\quad \mathrm{CF}-8$

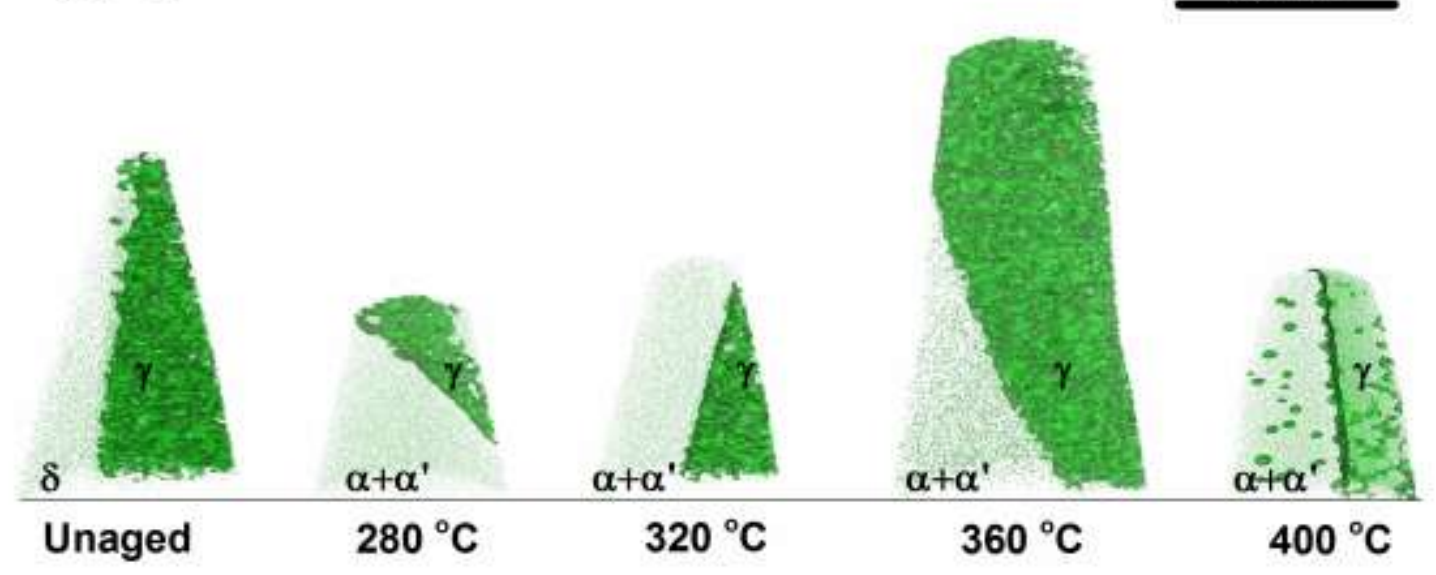

Figure 13 


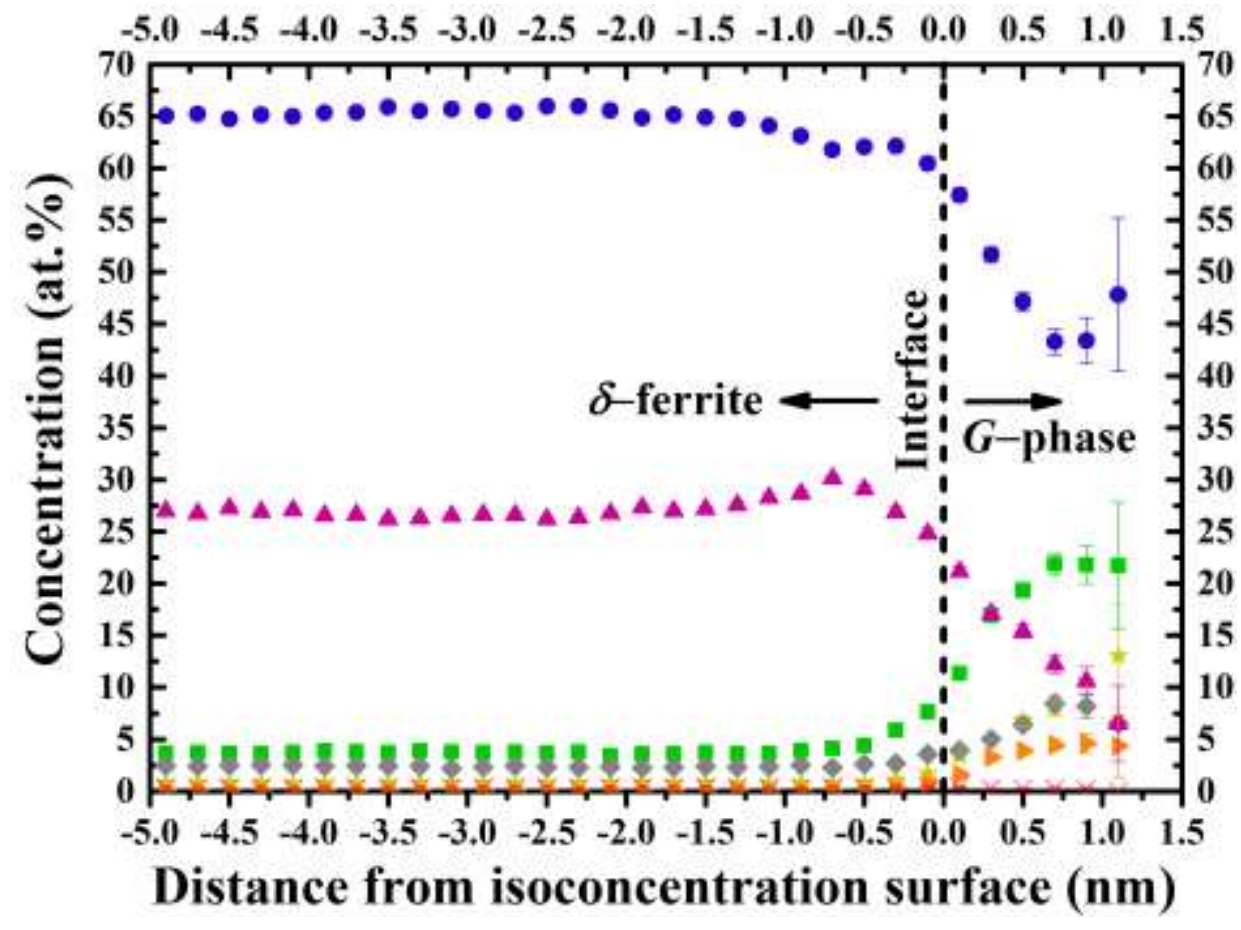

Figure 14 


\section{References}

[1] J. K. Sahu, U. Krupp, R. N. Ghosh, and H.-J. Christ, "Effect of $475{ }^{\circ} \mathrm{C}$ embrittlement on the mechanical properties of duplex stainless steel," Materials Science and Engineering: A, vol. 508, no. 1-2, pp. 1-14, May 2009.

[2] Y. Chen, B. Alexandreanu, K. Natesan, and A. S. Rao, "Environmentally assisted cracking and irradiation embrittlement of CF-8 and CF-8M cast austenitic stainless steels in highpurity water," Nuclear Energy Agency of the OECD (NEA), 2015.

[3] R. P. Kolli et al., "Characterization of Element Partitioning at the Austenite/Ferrite Interface of asCast CF-3 and CF-8 Duplex Stainless Steels," Microscopy and Microanalysis, no. Supplement S3, pp. 365-366, Aug. 2015.

[4] Z.-X. Wang, F. Xue, W.-H. Guo, H.-J. Shi, G.-D. Zhang, and G. Shu, "Investigation of thermal aging damage mechanism of the Cast Duplex Stainless Steel," Nuclear Engineering and Design, vol. 240, no. 10, pp. 2538-2543, Oct. 2010.

[5] M. K. Miller and J. Bentley, "APFIM and AEM investigation of CF8 and CF8M primary coolant pipe steels," Materials Science and Technology, vol. 6, no. 3, pp. 285-292, Mar. 1990.

[6] F. Danoix and P. Auger, "Atom Probe Studies of the Fe-Cr System and Stainless Steels Aged at Intermediate Temperature: A Review," Materials Characterization, vol. 44, no. 12, pp. 177-201, Jan. 2000.

[7] P. Auger, F. Danoix, A. Menand, S. Bonnet, J. Bourgoin, and M. Guttmann, "Atom probe and transmission electron microscopy study of aging of cast duplex stainless steels," Materials Science and Technology, vol. 6, no. 3, pp. 301-313, Mar. 1990.

[8] P. McConnell, W. Sheckherd, and D. Norris, "Properties of thermally embrittled cast duplex stainless steel," Journal of Materials Engineering, vol. 11, no. 3, pp. 227-236, Dec. 1989.

[9] P. H. Pumphrey and K. N. Akhurst, "Aging kinetics of CF3 cast stainless steel in temperature range $300-400^{\circ}$ C," Materials Science and Technology, vol. 6, no. 3, pp. $211-$ 220, Mar. 1990.

[10] H. M. Chung, "Aging and life prediction of cast duplex stainless steel components," International Journal of Pressure Vessels and Piping, vol. 50, no. 1, pp. 179-213, Jan. 1992.

[11] H. M. Chung and T. R. Leax, "Embrittlement of laboratory and reactor aged CF3,CF8, and CF8M duplex stainless steels," Materials Science and Technology, vol. 6, no. 3, pp. 249262, Mar. 1990.

[12] C. Pareige, S. Novy, S. Saillet, and P. Pareige, "Study of phase transformation and mechanical properties evolution of duplex stainless steels after long term thermal ageing (>20 years)," Journal of Nuclear Materials, vol. 411, no. 1-3, pp. 90-96, Apr. 2011.

[13] O. K. Chopra, Initial assessment of the mechanisms and significance of low-temperature embrittlement of cast stainless steels in LWR systems. Division of Engineering, Office of Nuclear Regulatory Research, U.S. Nuclear Regulatory Commission, 1990.

[14] O. K. Chopra and G. Ayrault, "Aging degradation of cast stainless steel: Status and program," Nuclear Engineering and Design, vol. 86, no. 1, pp. 69-77, Apr. 1985.

[15] O. K. Chopra and H. M. Chung, "Aging of cast duplex stainless steels in LWR systems," Nuclear Engineering and Design, vol. 89, no. 2-3, pp. 305-318, Nov. 1985. 
[16] T. S. Byun, Y. Yang, N. R. Overman, and J. T. Busby, "Thermal Aging Phenomena in Cast Duplex Stainless Steels," Journal of the Minerals, Metals, and Materials Society, vol. 68, no. 2, pp. 507-516, Nov. 2015.

[17] S. Bonnet, J. Bourgoin, J. Champredonde, D. Guttmann, and M. Guttmann, "Relationship between evolution of mechanical properties of various cast duplex stainless steels and metallurgical and aging parameters: outline of current EDF programmes," Materials Science and Technology, vol. 6, no. 3, pp. 221-229, Mar. 1990.

[18] S. Mburu et al., "Atom Probe Tomography Analysis of the Local Chemical Environment at the Austenite/Ferrite Interfaces of Cast Duplex Stainless Steels," "Engineering Innovation for Global Sustainability”: Proceedings of the 14th LACCEI International MultiConference for Engineering, Education, and Technology, Jul. 2016.

[19] O. K. Chopra and H. M. Chung, "Effect of Low-Temperature Aging on the Mechanical Properties of Cast Stainless Steels," Argonne National Lab., IL (USA), CONF-871232-2, Jul. 1987.

[20] T. Hamaoka, A. Nomoto, K. Nishida, K. Dohi, and N. Soneda, "Accurate determination of the number density of G-phase precipitates in thermally aged duplex stainless steel," Philosophical Magazine, vol. 92, no. 22, pp. 2716-2732, Aug. 2012.

[21] T. Hamaoka, A. Nomoto, K. Nishida, K. Dohi, and N. Soneda, "Effects of aging temperature on G-phase precipitation and ferrite-phase decomposition in duplex stainless steel," Philosophical Magazine, vol. 92, no. 34, pp. 4354-4375, Dec. 2012.

[22] J. Emo, C. Pareige, S. Saillet, C. Domain, and P. Pareige, "Kinetics of secondary phase precipitation during spinodal decomposition in duplex stainless steels: A kinetic Monte Carlo model - Comparison with atom probe tomography experiments," Journal of Nuclear Materials, vol. 451, no. 1-3, pp. 361-365, Aug. 2014.

[23] D. Isheim, R. P. Kolli, M. E. Fine, and D. N. Seidman, "An atom-probe tomographic study of the temporal evolution of the nanostructure of $\mathrm{Fe}-\mathrm{Cu}$ based high-strength low-carbon steels," Scripta materialia, vol. 55, no. 1, pp. 35-40, 2006.

[24] A. Devaraj et al., "Three-dimensional nanoscale characterisation of materials by atom probe tomography," International Materials Reviews, Jan. 2017.

[25] J. W. Cahn, “On spinodal decomposition," Acta Metallurgica, vol. 9, no. 9, pp. 795-801, Sep. 1961.

[26] J. W. Cahn and J. E. Hilliard, "Free Energy of a Nonuniform System. I. Interfacial Free Energy," The Journal of Chemical Physics, vol. 28, no. 2, pp. 258-267, Feb. 1958.

[27] M. K. Miller, J. M. Hyde, M. G. Hetherington, A. Cerezo, G. D. W. Smith, and C. M. Elliott, "Spinodal decomposition in Fe-Cr alloys: Experimental study at the atomic level and comparison with computer models-I. Introduction and methodology," Acta Metallurgica et Materialia, vol. 43, no. 9, pp. 3385-3401, Sep. 1995.

[28] M. K. Miller, A. Cerezo, M. G. Hetherington, and J. M. Hyde, "Estimation of composition amplitude: Pa and LBM versus V," Surface Science, vol. 266, no. 1, pp. 446-452, Apr. 1992.

[29] M. K. Miller, K. F. Russell, K. Thompson, R. Alvis, and D. J. Larson, "Review of Atom Probe FIB-Based Specimen Preparation Methods," Microscopy and Microanalysis, vol. 13, no. 06, pp. 428-436, Dec. 2007.

[30] K. Thompson, D. Lawrence, D. J. Larson, J. D. Olson, T. F. Kelly, and B. Gorman, "In situ site-specific specimen preparation for atom probe tomography," Ultramicroscopy, vol. 107, no. 2-3, pp. 131-139, Feb. 2007. 
[31] R. P. Kolli and F. Meisenkothen, "A Focused Ion Beam Specimen Preparation Method to Minimize Gallium Ion Concentration in Copper Atom-Probe Tomography Specimen Tips," Microscopy and Microanalysis, vol. 20, no. S3, pp. 350-351, 2014.

[32] O. C. Hellman, J. A. Vandenbroucke, J. Rüsing, D. Isheim, and D. N. Seidman, “Analysis of Three-dimensional Atom-probe Data by the Proximity Histogram," Microscopy and Microanalysis, vol. 6, no. 05, pp. 437-444, Sep. 2000.

[33] R. P. Kolli and D. N. Seidman, "Comparison of compositional and morphological atomprobe tomography analyses for a multicomponent $\mathrm{Fe}-\mathrm{Cu}$ steel," Microscopy and Microanalysis, vol. 13, no. 4, pp. 272-284, Aug. 2007.

[34] B. Gault, M. P. Moody, J. M. Cairney, and S. P. Ringer, Atom Probe Microscopy, vol. 160. New York, NY: Springer New York, 2012.

[35] M. D. Mathew, L. M. Lietzan, K. L. Murty, and V. N. Shah, "Low temperature aging embrittlement of CF-8 stainless steel," Materials Science and Engineering: A, vol. 269, no. 1-2, pp. 186-196, Aug. 1999.

[36] W. F. Michaud, P. T. Toben, W. K. Soppet, and O. K. Chopra, Tensile-property characterization of thermally aged cast stainless steels. Washington, DC: Division of Engineering, Office of Nuclear Regulatory Research, U.S. Nuclear Regulatory Commission, 1994.

[37] S. C. Schwarm, R. P. Kolli, E. Aydogan, S. Mburu, and S. Ankem, "Characterization of phase properties and deformation in ferritic-austenitic duplex stainless steels by nanoindentation and finite element method," Materials Science and Engineering: A, vol. 680, pp. 359-367, 2017.

[38] S. C. Schwarm, S. Mburu, R. P. Kolli, D. E. Perea, J. Liu, and S. Ankem, "Mechanical and Microstructural Effects of Thermal Aging on Cast Duplex Stainless Steels by Experiment and Finite Element Method," in Mechanical and Creep Behavior of Advanced Materials, I. Charit, Y. T. Zhu, S. A. Maloy, and P. K. Liaw, Eds. Springer International Publishing, 2017, pp. 253-262.

[39] S. L. Li et al., "Microstructure evolution and impact fracture behaviors of Z3CN20-09M stainless steels after long-term thermal aging," Journal of Nuclear Materials, vol. 433, no. 1-3, pp. 41-49, Feb. 2013.

[40] Y. H. Yao, J. F. Wei, and Z. P. Wang, "Effect of long-term thermal aging on the mechanical properties of casting duplex stainless steels," Materials Science and Engineering: A, vol. 551, pp. 116-121, Aug. 2012.

[41] P. D. Southwick and R. W. K. Honeycombe, "Precipitation of M23C6 at austenite/ferrite interfaces in duplex stainless steel," Metal Science, vol. 16, no. 10, pp. 475-482, Oct. 1982.

[42] J. Y. Xie, N. X. Chen, L. D. Teng, and S. Seetharaman, "Atomistic study on the site preference and thermodynamic properties for Cr23-xFexC6," Acta Materialia, vol. 53, no. 20, pp. 5305-5312, Dec. 2005.

[43] J. J. Han, C. P. Wang, X. J. Liu, Y. Wang, and Z.-K. Liu, "First-principles calculation of structural, mechanical, magnetic and thermodynamic properties for $\gamma-\mathrm{M} 23 \mathrm{C} 6(\mathrm{M}=\mathrm{Fe}$, Cr) compounds," Journal of Physics: Condensed Matter, vol. 24, no. 50, p. 505503, 2012.

[44] J. Janovec, A. Vyrostkova, and M. Svoboda, "Influence of tempering temperature on stability of carbide phases in $2.6 \mathrm{cr}-0.7 \mathrm{mo}-0.3 \mathrm{v}$ steel with various carbon content," Metallurgical and Materials Transactions A, vol. 25, no. 2, pp. 267-275, Feb. 1994. 
[45] T. S. Byun, Y. Yang, N. R. Overman, and J. T. Busby, "Thermal Aging Phenomena in Cast Duplex Stainless Steels," Journal of the Minerals, Metals, and Materials Society, vol. 68, no. 2, pp. 507-516, Feb. 2016.

[46] Phase Transformations in Metals and Alloys, Third Edition, 3 edition. Boca Raton, FL: CRC Press, 2009.

[47] R. W. Balluffi, S. Allen, and W. C. Carter, Kinetics of Materials. John Wiley \& Sons, 2005.

[48] R. P. Kolli and D. N. Seidman, "Co-Precipitated and Collocated Carbides and Cu-Rich Precipitates in a Fe-Cu Steel Characterized by Atom-Probe Tomography," Microscopy and Microanalysis, vol. 20, no. 06, pp. 1727-1739, Dec. 2014.

[49] P. I. Williams and R. G. Faulkner, "Chemical volume diffusion coefficients for stainless steel corrosion studies," Journal of Materials Science, vol. 22, no. 10, pp. 3537-3542, Oct. 1987.

[50] R. W. K. Honeycombe and R. F. Mehl, "Transformation from austenite in alloy steels," Metallurgical Transactions A, vol. 7, no. 7, pp. 915-936, Jul. 1976.

[51] H. K. D. H. Bhadeshia, "Diffusional formation of ferrite in iron and its alloys," Progress in Materials Science, vol. 29, no. 4, pp. 321-386, Jan. 1985.

[52] J. Zhou, J. Odqvist, M. Thuvander, and P. Hedström, "Quantitative evaluation of spinodal decomposition in Fe-Cr by atom probe tomography and radial distribution function analysis," Microscopy and Microanalysis, vol. 19, no. 3, pp. 665-675, Jun. 2013.

[53] T. Kuwajima, Y. Saito, and Y. Suwa, "Kinetics of phase separation in iron-based ternary alloys. II. Numerical simulation of phase separation in $\mathrm{Fe}-\mathrm{Cr}-\mathrm{X}(\mathrm{X}=\mathrm{Mo}, \mathrm{Cu})$ ternary alloys," Intermetallics, vol. 11, no. 11-12, pp. 1279-1285, 2003.

[54] Y. S. Yoshihiro Suwa, "Kinetics of Phase Separation in Fe-Cr-Mo Ternary Alloys," Materials Transactions A, vol. 43, no. 2, pp. 271-276, 2002.

[55] K. H. Lo, C. H. Shek, and J. K. L. Lai, "Recent developments in stainless steels," Materials Science and Engineering: R: Reports, vol. 65, no. 4-6, pp. 39-104, May 2009.

[56] Y. Matsukawa et al., "The two-step nucleation of G-phase in ferrite," Acta Materialia, vol. 116, pp. 104-113, Sep. 2016.

[57] F. Vurpillot, A. Bostel, and D. Blavette, "Trajectory overlaps and local magnification in three-dimensional atom probe," Applied Physics Letters, vol. 76, no. 21, pp. 3127-3129, May 2000.

[58] T. R. Leax, S. S. Brenner, and J. A. Spitznagel, "Atom probe examination of thermally ages CF8M cast stainless steel," Metallurgical Transactions A, vol. 23, no. 10, pp. 2725-2736, Oct. 1992.

[59] T. Yamada, S. Okano, and H. Kuwano, "Mechanical property and microstructural change by thermal aging of SCS14A cast duplex stainless steel," Journal of Nuclear Materials, vol. 350, no. 1, pp. 47-55, Mar. 2006.

[60] W. Guo, D. A. Garfinkel, J. D. Tucker, D. Haley, G. A. Young, and J. D. Poplawsky, “An atom probe perspective on phase separation and precipitation in duplex stainless steels," Nanotechnology, vol. 27, no. 25, p. 254004, 2016. 